This PDF is a selection from a published volume from the National Bureau of Economic Research

Volume Title: Education, Skills, and Technical Change: Implications for Future US GDP Growth

Volume Authors/Editors: Charles R. Hulten and Valerie A. Ramey, editors

Volume Publisher: University of Chicago Press

Volume ISBNs: 978-0-226-56780-8 (cloth); 978-0-226-56794-5 (electronic); 0-226-56780-X (cloth)

Volume URL: http://www.nber.org/books/hult-12

Conference Date: October 16-17, 2015

Publication Date: December 2018

Chapter Title: Online Postsecondary Education and Labor Productivity

Chapter Author(s): Caroline M. Hoxby

Chapter URL: http://www.nber.org/chapters/c13709

Chapter pages in book: (p. $401-460)$ 


\title{
Online Postsecondary Education and Labor Productivity
}

\author{
Caroline M. Hoxby
}

\subsection{The Promise and Possible Perils of Online Postsecondary Education}

Could the availability of online postsecondary education substantially raise human capital and labor productivity in the United States and around the world? Online educational platforms potentially make postsecondary education available to people who, owing to their locations or time constraints, might otherwise lack access. Because the cost structure of online education differs from that of in-person education (online education is thought to have low marginal costs), the productivity (causal improvement in outcomes per dollar spent) of online schools could be high even if they did not improve students' outcomes more than in-person schools. Also, online platforms lend themselves to certain types of education, such as computer programming and technical design, where interacting with a computer is naturally an important part of the learning process. This suggests that online

Caroline M. Hoxby is the Scott and Donya Bommer Professor in Economics at Stanford University and a research associate and director of the Economics of Education Program at the National Bureau of Economic Research.

The opinions expressed in this chapter are those of the author alone and do not necessarily represent the views of the US Internal Revenue Service or the US Department of the Treasury. This work is a component of a larger project examining the effects of federal tax expenditures and on-budget expenditures related to higher education. The computations in this chapter were produced incidentally in the process of the Hoxby (2018) study, which relies on selected, deidentified data accessed through contract TIR-NO-12-P-00378 and TIR-NO-15-P-00059 with the Statistics of Income Division at the US Internal Revenue Service. The author gratefully acknowledges the help of Barry W. Johnson, Michael Weber, and Brian G. Raub of the Statistics of Income Division, Internal Revenue Service. The author is grateful for suggestions and very useful comments from her discussant, Nora Gordon, and from Katherine Abraham, John Bound, David Deming, Charles Hulten, Jennifer Hunt, Valerie Ramey, and conference participants. For acknowledgments, sources of research support, and disclosure of the author's material financial relationships, if any, please see http://www.nber.org/chapters/c13709.ack. 
platforms might disproportionately expand the availability of education that trains people for technical, rapidly growing industries that routinely complain that they are unable to find a sufficient number of workers with the skills they require. Such hopeful views of online education are reflected in quotations like the following: "For those who believe that higher education should be personalized, inexpensive, as accessible to working mothers as it is to third-generation Yalies, and geared toward helping students acquire skills that employers actually desire, utopia is on the horizon."1

On the other hand, the flexibility and paucity of face-to-face contact inherent in online education may mean that only highly self-disciplined students learn well on such platforms. These may not be the people who tend to enroll in online education. Indeed, online education is controversial among policymakers, especially federal ones, because the sector's students generate a disproportionate share of defaults on and repayment issues with student loans. ${ }^{2}$ They also account for a disproportionate share of tax expenditures on tuition and fees (see below). ${ }^{3}$ Moreover, in federal undercover investigations and audits, online postsecondary institutions have been disproportionately found engaging in deceptive marketing, fraud, academic dishonesty, low course-grading standards, and other violations of education regulations. ${ }^{4}$

In short, online postsecondary education may be a windfall for taxpayers and the economy more broadly: an inexpensive way for people to acquire the cutting-edge skills they need to be productive. Online students may earn returns disproportionate to their opportunity costs and direct schooling costs. Alternatively, online postsecondary education may be a liability for taxpayers and the economy: it may be a sector that takes funds from the federal taxpayers and students but that generates insufficient skills to repay those takings.

The first step in understanding whether online postsecondary education is a windfall or a liability is determining its return on investment (ROI) based on earnings. This is the primary goal of this study. Because proponents of online education also argue, however, that it enables people to reallocate themselves from slow-growing, obsolescent industries to fast-growing industries with rising labor productivity, this study also investigates direct evidence for that argument. Such reallocation could benefit all workers through general equilibrium effects. Thus, we are justified in looking for evidence

1. Beato (2014); emphasis added. His article emphasizes online courses that give students computer-related skills such as "Building a Search Engine," "Programming a Robotic Car," and "HTML5 Game Development." Clayton Christensen has made something of a career of arguing that online education will have low costs, generate instructional innovation, engage students with technology, and disproportionately fulfill employers' needs for cutting-edge skills. See, for instance, Christensen and Eyring (2011) and Christensen and Horn (2013). See also Waldrop (2013).

2. See Looney and Yannelis (2015).

3. Author's calculations. See below.

4. United States General Accountability Office (2010, 2011). 
of reallocation, not merely evidence of increases in online students' own postenrollment earnings.

To achieve these goals, this study analyzes longitudinal data on nearly every person who engaged substantially in online postsecondary education between 1999 and 2011. These are ideal data for estimating ROIs and studying labor reallocation. As a result, this study is a good complement to (though not a good substitute for) previous studies of online education, which have often focused on a small number of online courses or a single provider of online education. ${ }^{5}$ Such studies help us understand what happens in an online class, whereas this study should help us test broad theories about online education and help us evaluate its contribution to the economy.

The remainder proceeds as follows. In section 11.2, I define online postsecondary education and describe its explosive growth since 2005. The data are described in section 11.3. Section 11.4 describes who enrolls in online education, how long they engage in coursework, and how much they and taxpayers pay for it. In section 11.5, I use figures to show how earnings evolve before and after individuals' episodes of online enrollment. Although this section does not contain calculations of ROI, the figures contain so much information that readers will be able to anticipate ROIs. In section 11.6, I lay out my empirical strategy for estimating ROIs. The primary challenge is that some self-selection into online education may be driven by events that negatively affect earnings. This phenomenon, known as "Ashenfelter's Dip," was first identified as a problem in efforts to estimate the effects of job training. ${ }^{6}$ When negative earnings events induce people to engage in training or online education, we have difficulty projecting what their earnings would have been in the absence of the training or education. In particular, we do not know whether their earnings would have bounced back on their own. Section 11.7 contains the ROI results. Section 11.8 investigates whether online students reallocate themselves toward industries that are associated with higher labor productivity, fast growth, or high technology. Section 11.9 makes calculations that show whether online education is a windfall or liability for taxpayers. Conclusions occupy section 11.10.

\subsection{The Recent, Explosive Growth in Online Postsecondary Enrollment}

Online postsecondary enrollment has grown very rapidly in recent years. Figures 11.1 and 11.2 show the number of students enrolled in coursework

5. For studies along these lines, see Bettinger et al. (2014), Bowen et al. (2014), Figlio, Rush, and Yin (2013), Xu and Jaggars (2013), Hart, Friedmann, and Hill (2014), and Streich (2014). Economic research regarding online education is still fairly limited. A brief survey might include Cowen and Tabarrok (2014), Deming, Goldin, and Katz (2012), Deming et al. (2015), Deming, Lovenheim, and Patterson (forthcoming), Ho et al. (2014), Hoxby (2014), and McPherson and Bacow (2015). None of the aforementioned studies have sufficient longitudinal data on earnings and costs to estimate ROIs.

6. The seminal paper is Ashenfelter and Card (1985). 


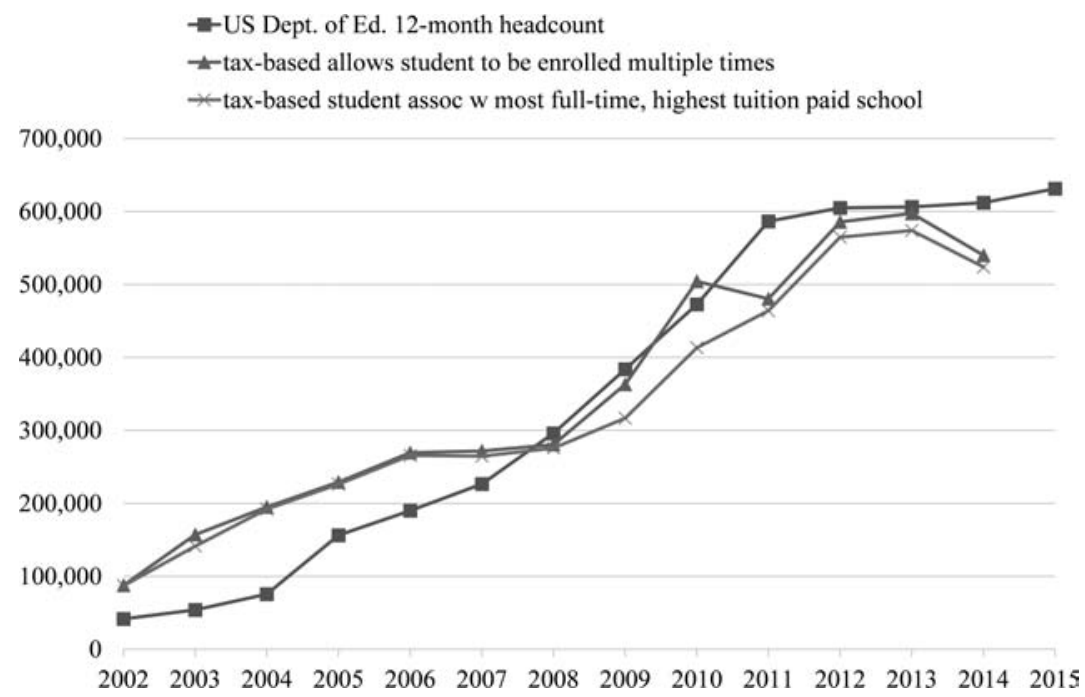

Fig. 11.1 Enrollment in postsecondary programs that are exclusively online (total: undergraduate and graduate, full- and part-time)

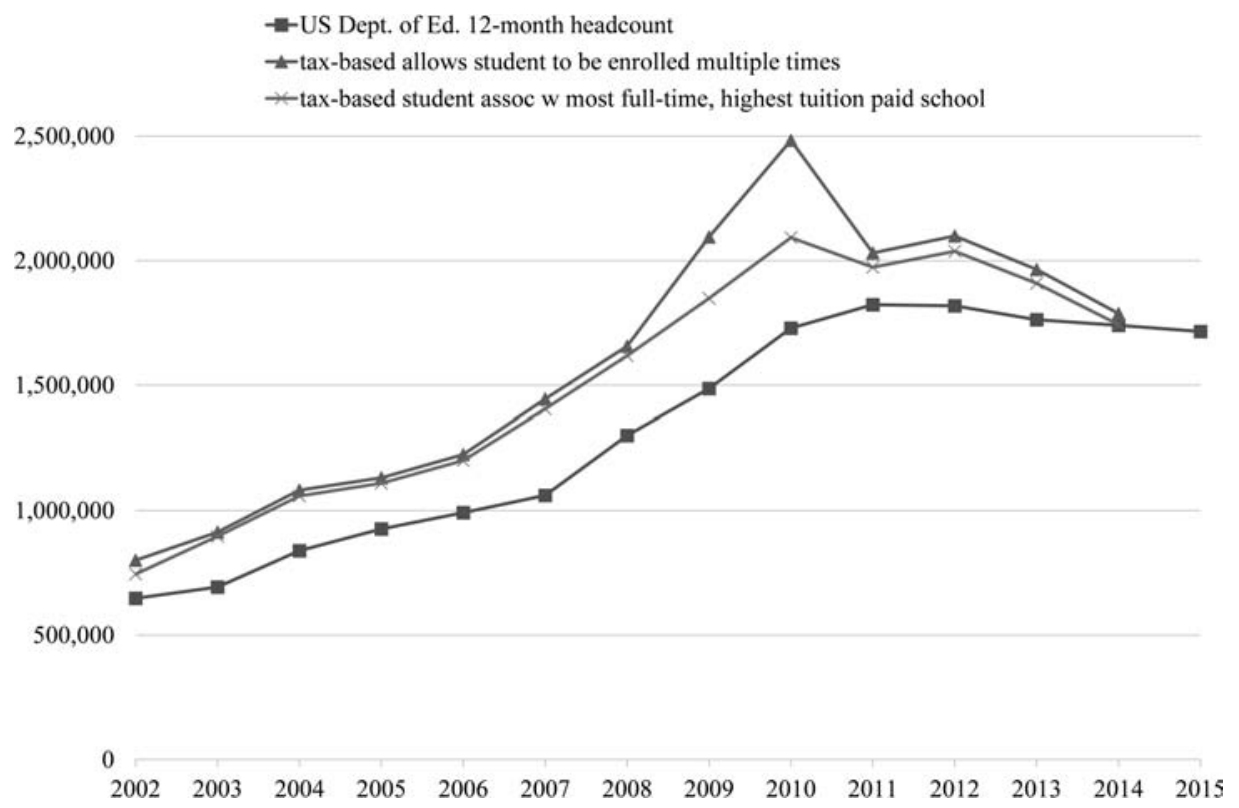

Fig. 11.2 Enrollment in postsecondary programs that are mainly online (total: undergraduate and graduate, full- and part-time) 
that is, respectively, exclusively and mainly online. (The exact definition of "mainly online" is given below, but think of it as more than half online.) Both figures show that enrollment grew dramatically after 2005. This is not an accident or an effect of broadband access. Rather, 2005 corresponds to the year in which the US Department of Education eliminated the " 50 percent rule" that required an institution's enrollment to be at least 50 percent in-person for its students to qualify for federal tax credits, tax deductions, grants, loans, and other financial aid. ${ }^{7}$ This rule constrained the growth of online education because an institution had to recruit and have a campus (or campuses) to support one in-person student for each online student.

One line on each figure shows the US Department of Education's twelvemonth head count, including all undergraduate and graduate students who enroll in a school year, regardless of whether they are full- or part-time. This number should correspond closely to enrollment figures based on tax data if we allow each student to count multiple times if he is enrolled at multiple institutions. This is the next line on each chart. The final line on each chart shows tax-data-based enrollment in which each student is counted only once and is associated with the institution where he is at least half-time and, if this leaves ambiguity, to which the highest tuition is paid on his behalf. ${ }^{8}$

Figure 11.1 shows that, up through 2002, fewer than 100,000 students enrolled each year in education that was exclusively online. By 2013, the number of students enrolled in exclusively online education was about 600,000 , more than six times the number a decade previously. Walden University, Aspen University, and Argosy University are examples of exclusively online institutions. They truly have no campus or classrooms - only an office with staff who manage finances, keep records, and coordinate web-based instruction. They offer a variety of undergraduate and graduate degree programs but, typically, their programs are nonselective. That is, they enroll any student who has completed the previous level of education - a high school diploma or General Education Development (GED) certificate in the case of undergraduates.

Figure 11.2 shows that enrollment in mainly online education approximately tripled over the same period. It was about 700,000 in 2002 , but it was about $1,700,000$ in $2012-2015$. However, this growth in overall enrollment understates the growth in online enrollment. Once they were released from the constraint of the 50 percent rule, mainly online institutions actually reduced the size and number of their brick-and-mortar campuses and

7. One might wonder how there could be any exclusively only students prior to 2005 given the 50 percent rule. First, some schools had experimental waivers from the rule. Second, the requirement applied to an institution as a whole, not program-by-program. Thus, the graduate students in a school could be exclusively only even if the undergraduates were not, and vice versa. See the next section for the question by which programs are classified.

8. See Hoxby (2018) for a detailed discussion and comparison of online enrollment data from the US Department of Education and from tax data. 


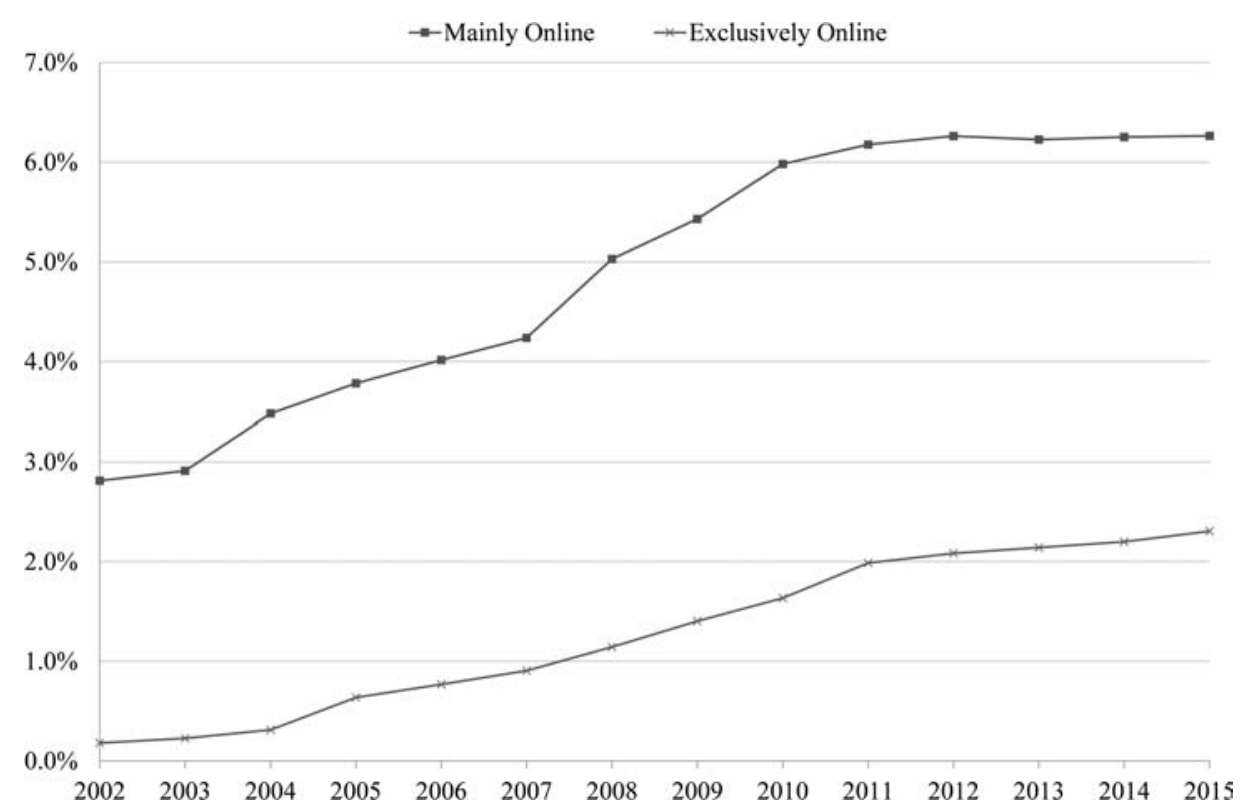

Fig. 11.3 Percentage of US postsecondary enrollment in exclusively and mainly online programs

shifted toward instruction that was increasingly online. ${ }^{9}$ Examples of mainly online institutions are The University of Phoenix, Kaplan University, DeVry University, and Liberty University.

Although the growth of online education is striking and shows no signs of abating, it is important to keep in mind that it is still far from the norm. Figure 11.3 shows that, even in 2015, it accounted for only 8.3 percent of total enrollment. Thus, students who self-select into online education are unusual as a statistical matter. This is a fact to keep in mind because it affects the empirical strategy I adopt.

\subsection{Data}

This study employs deidentified data from an IRS database for the years 1999 to 2014. It includes all people who engaged in exclusively or mainly online postsecondary education. (See below for the definition of an enrollment episode.) From Form 1098-T, an information return that postsecondary institutions file, are derived tuition and fee payments, whether the student is enrolled at least half-time, whether the student is enrolled in graduate studies, and scholarships and grants received by the student. These variables

9. See Deming, Lovenheim, and Patterson (forthcoming). 
are available regardless of whether the student actually files for tax credits or deductions for tuition and fees. From Forms 8917 and 8863, I derive the student's take-up of the tax credits and deductions for postsecondary tuition and fees. Wages and employment variables are derived from Form W-2, and these variables are available regardless of whether a person files an income tax return. From variants of Form 1040 are derived adjusted gross income and any postsecondary tax credits and deductions that are actually taken. ${ }^{10}$

For data on the share of an institution's courses that are taken online, I rely on the National Center for Education Statistics Integrated Postsecondary Education Data System (IPEDS). This is a data system to which nearly all postsecondary institutions must mandatorily report. IPEDS is also the source of numerous other institution-level, as opposed to studentlevel, variables: Pell grant revenue, total undergraduate student loans, total enrollment, and so on.

IPEDS asks postsecondary schools the following:

1. Are all programs at your institution offered exclusively via distance education?

2. How many degree/certificate-seeking undergraduates are (a) enrolled exclusively in distance education courses, (b) enrolled in some but not all distance education courses, or (c) not enrolled in any distance education course?

3. Repeat question (2) for non-degree/certificate-seeking undergraduates and for graduate students.

A student is classified as attending "exclusively online" if the answer to question (1) is yes or if the probability that he or she is enrolled in distance education is 100 percent based on the answers to questions (2) and (3). For instance, if a student were enrolled in graduate coursework, and all graduate students were enrolled exclusively in online courses (possibility 2[a]), then the student would be classified as exclusively online. Note that undergraduate and graduate students at the same institution could be classified differently.

A student's coursework is classified as "mainly online" if the probability that his or her courses are online is greater than 50 percent where the probability assigned to option (2)(a) is 100 percent, option (2)(b) is 50 percent, and option (2)(c) is 0 percent. ${ }^{11}$ Unfortunately, it is not possible to classify mainly online experiences more precisely. Clearly, the mainly online category is imprecise and contains students with a variety of online experiences.

A student's coursework is classified as "hardly online" if the probability that his or her courses are online is 10 percent or less where the probabilities

10. Forms 8917 and 8863 ensure that tax credits and deductions are properly mapped from filer to student when they are not the same person.

11. I assign 50 percent to option (2)(b) because many institutions were tightly bound by the 50 percent rule up through 2005 . In more recent years, the mainly online category has become, if anymore, more online. 
assigned to options (2)(a), (2)(b), and (2)(c) are the same as given above. Finally, I classify a student as hardly online and at a nonselective institution if his or her school will enroll any student with a high school degree or GED in undergraduate coursework or enroll any student with a baccalaureate degree in graduate coursework. Because nearly all exclusively online and mainly online institutions are nonselective, this final category (hardly online and nonselective) is the best comparison for online schools. Indeed, recent evidence suggests that it is these institutions that are most likely to lose students to online postsecondary schools. ${ }^{12}$ Put another way, students who attend nonselective institutions are more elastic between online and in-person settings than are students who attend selective ones.

The data include up to sixteen longitudinal observations for each person who enrolled between 1999 and 2014 in postsecondary education. However, given the explosive increase in online course-taking after 2005, the analysis of online students is strongly weighted toward the later years in the period. The descriptive statistics shown in the next section focus on students who were enrolled in 2013 so as to represent online education as its most current. ${ }^{13}$ (Descriptive statistics based on earlier years are available from the author.)

The enrollment and other variables reported on Form 1098-T are for calendar years rather than school years. They are based on the calendar year in which the institution received payment for tuition and fees. In most cases, a school year is divided across two calendar years and the first calendar year is the lesser of the two years that make up the first school year. For instance, suppose a freshman enrolls for the 2012/13 school year. If she pays for the autumn semester in September 2012 and the spring semester in January 2013, she will have two years of 1098-T-based enrollment, even if she enrolls for only a single school year. She will appear in calendar-year data in 2012, even though at least half (and usually more) of the months in the school year are in 2013. Three calendar years usually correspond to two school years, four calendar years to three school years, five calendar years to four school years, and so on. This is not always true, however, because a student may pay for her spring term in December or may begin her enrollment episode in January. In such cases, a calendar year corresponds to a school year.

For the purpose of this chapter, I need to define postsecondary "episodes" over which to compute ROI. For instance, if a student were to take a single term off and then return to his degree program, it would make sense to treat his enrollment as a single episode. The interruption would be so short that his learning experience would be truly connected before and after the break. Moreover, it would be nearly impossible to assess his returns from only the

12. See Deming, Lovenheim, and Patterson (forthcoming).

13. The IPEDS data for $2014 / 15$ are still preliminary, so I do not use 2014 for the descriptive statistics. 
first part of his enrollment. There would be only a brief period for him to earn income without his work competing with his studying. But, if a break of a single term should not define the end of an enrollment episode, what length of break should? In the interests of estimating ROI at all well (see empirical strategy section below), I define an enrollment episode to begin when a person who was not enrolled in any of the three preceding calendar years enrolls. The episode ends when he discontinues his enrollment for three consecutive calendar years. (The results are not sensitive to switching the nonenrollment length to two years or four years.) A student may have multiple enrollment episodes but, as shown below, only a small share of people do.

Since the first year of wage data is 1999, the first calendar year in which an episode could begin is 2002. Since the last year of wage data is 2014, the last calendar year in an episode could end is 2011 . Thus, the ROI calculations are for online students enrolled at some time between 2002 and 2011.

\subsection{A Description of Online Education in the United States}

This section attempts a rich description of online education in the United States, explaining who attends, the schools they attend, and how they pay for their coursework. Owing to the fact that the data are virtually population data, not sample data, all differences across the groups shown in the tables in this section are highly statistically significant. Therefore, I make no further mention of statistical significance. ${ }^{14}$

\subsubsection{Who Enrolls in Online Education?}

Table 11.1 shows us the characteristics of the students who enrolled in online postsecondary education in 2013. For comparison, it shows the same characteristics for 2013 students whose enrollment was (a) hardly online or (b) hardly online and nonselective. Table 11.2 shows the same characteristics broken down by undergraduate and graduate students.

The average age of online students is strikingly high: 36 for exclusively online students and 33.7 for mainly online students. Exclusively online and mainly online undergraduates average, respectively, 33.4 and 32.6 years of age. Exclusively online and mainly online graduate students average, respectively, 39.6 and 37 . These ages are much higher than those of hardly online students (25.5) or hardly online nonselective students (27.1). Despite their relatively advanced ages, the exclusively online and mainly online students are more likely to be undergraduates than to be graduate students. Sixty percent of the exclusively online students are undergraduates and 77.2 percent of the mainly online students are undergraduates. While these percentages

14. The $p$-values on differences are always less than 0.0001 , but there is, in any case, little consensus about how to interpret standard errors for population data. 


\begin{tabular}{|c|c|c|c|c|}
\hline & \multicolumn{4}{|c|}{$\begin{array}{l}\text { 2013/14 students at postsecondary } \\
\text { schools that are }\end{array}$} \\
\hline & $\begin{array}{l}100 \% \\
\text { online }\end{array}$ & $\begin{array}{l}\text { mainly } \\
\text { online }\end{array}$ & $\begin{array}{l}\text { hardly } \\
\text { online }\end{array}$ & $\begin{array}{l}\text { hardly online and } \\
\text { nonselective }\end{array}$ \\
\hline Average age & 36.0 & 33.7 & 25.5 & 27.1 \\
\hline Probability of being male (\%) & 41.4 & 36.5 & 44.3 & 41.5 \\
\hline $\begin{array}{l}\text { Probability enrolled at least half time } \\
(\%)\end{array}$ & 93.2 & 87.2 & 90.9 & 85.3 \\
\hline Probability is an undergraduate $(\%)$ & 60.0 & 77.2 & 89.0 & 99.0 \\
\hline $\begin{array}{l}\text { Own wages while enrolled } \\
\quad \text { (includes zeros) (\$) }\end{array}$ & 33,195 & 24,641 & 14,335 & 12,058 \\
\hline $\begin{array}{l}\text { Own household's income while enrolled } \\
\text { (includes zeros and negative) (\$) }\end{array}$ & 49,051 & 40,006 & 20,836 & 17,920 \\
\hline
\end{tabular}

Source: Data are from deidentified tax data combined with postsecondary institutions' classification data from IPEDS.

Notes: A postsecondary school is classified as "mainly online" if at least 50 percent of its courses are offered in an online or partially online way. A school is classified as "hardly online" if fewer than 10 percent of its courses are offered in an online or partially online way. Courses that serve "all students" are considered. A school is "nonselective" if any student with a high school diploma or GED may enroll in undergraduate classes or any student with a baccalaureate degree may enroll in graduate classes.

are lower than those for students who are hardly online ( 89 percent) or hardly online and nonselective (99 percent), we must conclude that many students who enroll online have been out of school for years or in school only sporadically since their teenage years.

The vast majority of exclusively online (93.2 percent) and mainly online (87.2 percent) students are enrolled at least half time. These percentages are fairly similar across undergraduate and graduate students. They are also fairly similar to those for hardly online and hardly online nonselective students. Thus, we can dismiss the idea that online education is dominated by students taking, say, a single course for professional development, as a hobby, or as an experiment. Most students appear to be attempting to complete coursework at a sufficient pace that they could potentially earn a degree or certificate.

In the same calendar year in which they are enrolled, exclusively online students earn average wages of $\$ 33,195$ : $\$ 27,118$ for undergraduates and $\$ 42,039$ for graduate students. These are not insubstantial amounts for students who are enrolled at least half time. Although the parallel average wage numbers for mainly online students are more modest $-\$ 24,641$ for all, $\$ 21,640$ for undergraduates, $\$ 34,780$ for graduate students - they nevertheless suggest that those enrolled online are juggling school with a significant amount of work. Hardly online and hardly online nonselective students earn much less: $\$ 14,335$ and $\$ 12,058$, respectively. This is undoubt- 


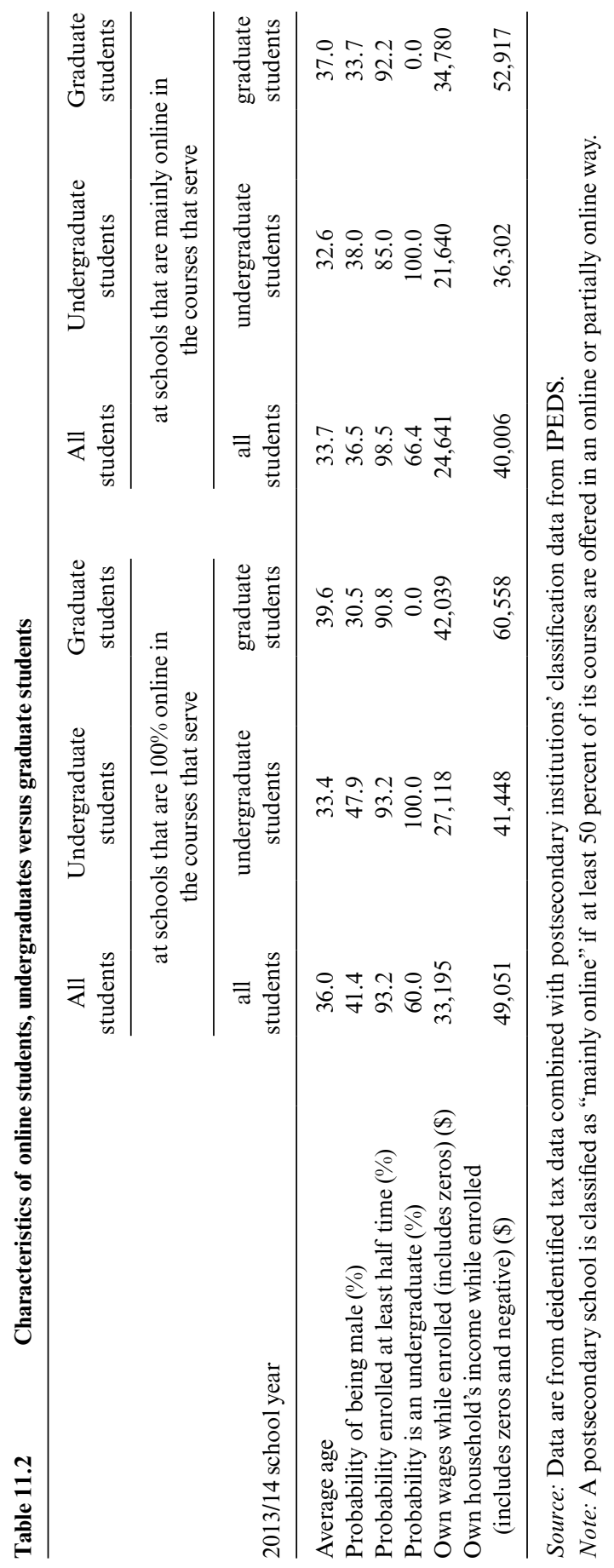

You are reading copyrighted material published by University of Chicago Press. 
edly partly because they are younger and thus likely to earn less per hour. However, part of their lower earnings is likely due to their working fewer hours while enrolled.

In the calendar year they are enrolled, the households of exclusively online and mainly online students have moderate incomes: $\$ 49,051$ and $\$ 40,006$, respectively. This puts them around the 45th and 35th percentiles of the income distribution among households who file taxes. It is important to observe that the students are earning the majority of this household income themselves: they would probably not be well supported by another earner if they were to cease working altogether while they were enrolled.

The share of students who are male hovers around 40 percent for all student groups: exclusively online, mainly online, hardly online, and hardly online nonselective. This male share is typical of US postsecondary education. The only notable sex-related statistic is that only 30 percent of exclusively online graduate students are male. This may be because teachers and nurses, who receive wage boosts if they earn certain graduate certificates or degrees, make up a good share of exclusively online students.

\subsubsection{Where Do Online Students Reside?}

Well before 2013/14, the school year described in the tables, the internet was available in all parts of the United States and fixed-wire high-speed internet service was available in all areas defined as urban by the census. (Note that urban areas include towns and small cities.) About half of rural households had fixed-wire high-speed internet available and satellite dishbased high-speed internet was available to the remaining half. ${ }^{15}$ Owing to online postsecondary education being potentially available almost everywhere, while brick-and-mortar schools were not, one might hypothesize that online students live disproportionately in small urban areas or sparsely populated areas. Table 11.3 (for all students) and table 11.4 (broken out for undergraduates and graduates) demonstrate that this hypothesis is correct only to a very slight extent. The tables are based on commuting zones $(\mathrm{CZs})$, which combine counties into units that reflect common commutes between workers' homes and their job locations. ${ }^{16}$ Because the typical student is in her midthirties and commutes to work, CZs are probably the geographic unit that best defines a student's brick-and-mortar postsecondary options.

Table 11.3 shows that 41.6 percent of students who attend exclusively online live in a CZ that has a population over the 90th percentile for CZs. Another 40.5 percent live in a $C Z$ with a population between the 75 th and 90th percentiles. Less than 6 percent live in a $\mathrm{CZ}$ with a population below

15. National Telecommunications and Information Administration, "US Broadband Availability: June 2010-June 2012." A Broadband Brief, published May 2013. https://www.ntia.doc .gov/files/ntia/publications/usbb_avail_report_05102013.pdf.

16. See United States Department of Agriculture, Economic Research Service (2016). See also Pew Charitable Trusts (2016). 


\begin{tabular}{|c|c|c|c|c|}
\hline & \multicolumn{4}{|c|}{$\begin{array}{l}\text { 2013/14 students at postsecondary } \\
\text { schools that are }\end{array}$} \\
\hline & $\begin{array}{l}100 \% \\
\text { online }\end{array}$ & $\begin{array}{c}\text { mainly } \\
\text { online }\end{array}$ & $\begin{array}{l}\text { hardly } \\
\text { online }\end{array}$ & $\begin{array}{c}\text { hardly } \\
\text { online and } \\
\text { nonselective }\end{array}$ \\
\hline $\mathrm{CZ}$ pop. $\leq 15,000(\leq 10$ th percentile of $\mathrm{CZs})$ & 0.2 & 0.3 & 0.1 & 0.1 \\
\hline CZ pop. $>15,000$ and $\leq 40,000(10-25$ th percentile of $\mathrm{CZs})$ & 0.6 & 2.1 & 0.3 & 0.4 \\
\hline CZ pop. $>40,000$ and $\leq 115,000$ (25-50th percentile of CZs) & 4.7 & 5.4 & 2.6 & 2.6 \\
\hline $\mathrm{CZ}$ pop. $>115,000$ and $\leq 300,000(50-75$ th percentile of $\mathrm{CZs})$ & 12.5 & 13.5 & 7.3 & 7.7 \\
\hline CZ pop. $>300,000$ and $\leq 1,600,000$ (75-90th percentile of CZs) & 40.5 & 37.6 & 32.4 & 37.5 \\
\hline CZ pop. $>1,600,000(>90$ th percentile of CZs) & 41.6 & 41.2 & 57.3 & 51.6 \\
\hline $\mathrm{CZ}$ density $\leq 7.75(\leq 10$ th percentile of $\mathrm{CZs})$ & 1.0 & 1.4 & 0.3 & 0.5 \\
\hline $\mathrm{CZ}$ density $>7.75$ and $\leq 24(10-25$ th percentile of $\mathrm{CZs})$ & 3.4 & 5.0 & 1.7 & 1.7 \\
\hline $\mathrm{CZ}$ density $>24$ and $\leq 63$ (25-50th percentile of CZs) & 10.1 & 10.4 & 5.4 & 6.4 \\
\hline $\mathrm{CZ}$ density $>63$ and $\leq 143(50-75$ th percentile of $\mathrm{CZs})$ & 20.7 & 18.8 & 13.3 & 14.7 \\
\hline $\mathrm{CZ}$ density $>143$ and $\leq 320$ (75-90th percentile of $\mathrm{CZs})$ & 26.7 & 27.6 & 25.1 & 21.2 \\
\hline $\mathrm{CZ}$ density $>320$ (> 90th percentile of CZs) & 38.2 & 36.9 & 54.2 & 55.5 \\
\hline
\end{tabular}

Source: Data are from deidentified tax data combined with postsecondary institutions' classification data from IPEDS. The source of CZ data is United States Department of Agriculture, Economic Research Service (2016).

Notes: "CZ" means commuting zone. See text for a definition. A postsecondary school is classified as "mainly online" if at least 50 percent of its courses are offered in an online or partially online way. A school is classified as "hardly online" if fewer than 10 percent of its courses are offered in an online or partially online way. Courses that serve "all students" are considered. A school is "nonselective" if any student with a high school diploma or GED may enroll in undergraduate classes or any student with a baccalaureate degree may enroll in graduate classes.

the 50th percentile for CZs. The numbers for students who attend mainly online are similar: 41.2 percent live in CZs with populations above the 90th percentile, 37.6 percent live in CZs with populations between the 75th and 90 th percentiles, and less than 8 percent live in a $\mathrm{CZ}$ with a population below the 50th percentile. Thus, the notion that the typical online student lives in a small urban area is wrong.

Table 11.3 shows parallel statistics for students who attend schools that are hardly online or hardly online and nonselective. Interestingly, although such students are more likely to live in CZs with large populations, the differences are not stark. For instance, among students enrolled in schools that are hardly online and nonselective, 51.6 percent live in a $\mathrm{CZ}$ with a population above the 90th percentile, 37.5 percent live in a $\mathrm{CZ}$ with a population between the 75th and 90th percentiles, and 3.1 percent live in a $\mathrm{CZ}$ with a population below the 50th percentile.

The notion that the typical online student lives in a sparsely populated area is also wrong. Among students who attend exclusively online, only 4.4 percent live in CZs with a population density below the 25 th percentile 
for CZs; 38.2 percent live in CZs with a population density above the 90th percentile. Similarly, among students who attend mainly online, only 6.4 percent live in CZs with a population density below the 25 th percentile, and 36.9 percent live in CZs with a population density above the 90th percentile. Students who are enrolled at schools that are hardly online are somewhat more likely to live in densely populated CZs, but - again - the differences are not striking.

Table 11.4 shows that within a category (exclusively online, mainly online) undergraduates tend to be distributed across CZs in a manner that is very similar to how graduate students are distributed. Thus, both the typical online undergraduate and the typical online graduate student live in CZs with large, dense populations.

\subsubsection{The Highest Degree and Control of Online Schools}

US postsecondary institutions are often characterized by the highest degree they offer. This may be a certificate (a "less-than-two-year" school), an associate's degree (a "two-year" school), a baccalaureate degree (a "fouryear" school), or some graduate degree (a "more-than-four-year" school). Most students who attend nonselective schools are at two-year or less-thantwo-year institutions. ${ }^{17}$

In addition, each US postsecondary institution may be a public school (controlled by a government), a private nonprofit, or a private for-profit. Although the for-profit sector still accounts for a small share of total US enrollment, it has grown rapidly in recent years. ${ }^{18}$ Much of this growth has occurred at schools that are exclusively or mainly online. Thus, it should be no surprise that online students disproportionately attend for-profit institutions. What may be more surprising, since exclusively online and mainly online institutions are nearly all nonselective, is that the vast majority of online students attend schools classified as four-year or more-than-fouryear institutions.

Table 11.5, which contains results for all students, shows that 76.8 percent of students who are enrolled exclusively online attend for-profit schools that offer the baccalaureate or a higher degree. Another 21.0 percent attend private nonprofit schools that offer the baccalaureate or a higher degree. This leaves only tiny shares who attend public schools or who attend schools that do not offer at least a baccalaureate degree. Students who attend mainly online are more evenly split between schools that offer at least the baccalaureate degree and that are for-profit (37.7 percent) or nonprofit (44.2 percent). Nonnegligible shares attend public four-year institutions (10.2 percent) or public two-year institutions (6.7 percent).

All of this is in sharp contrast to the corresponding statistics for students

17. See table 11.5.

18. See Deming, Goldin, and Katz (2012). 


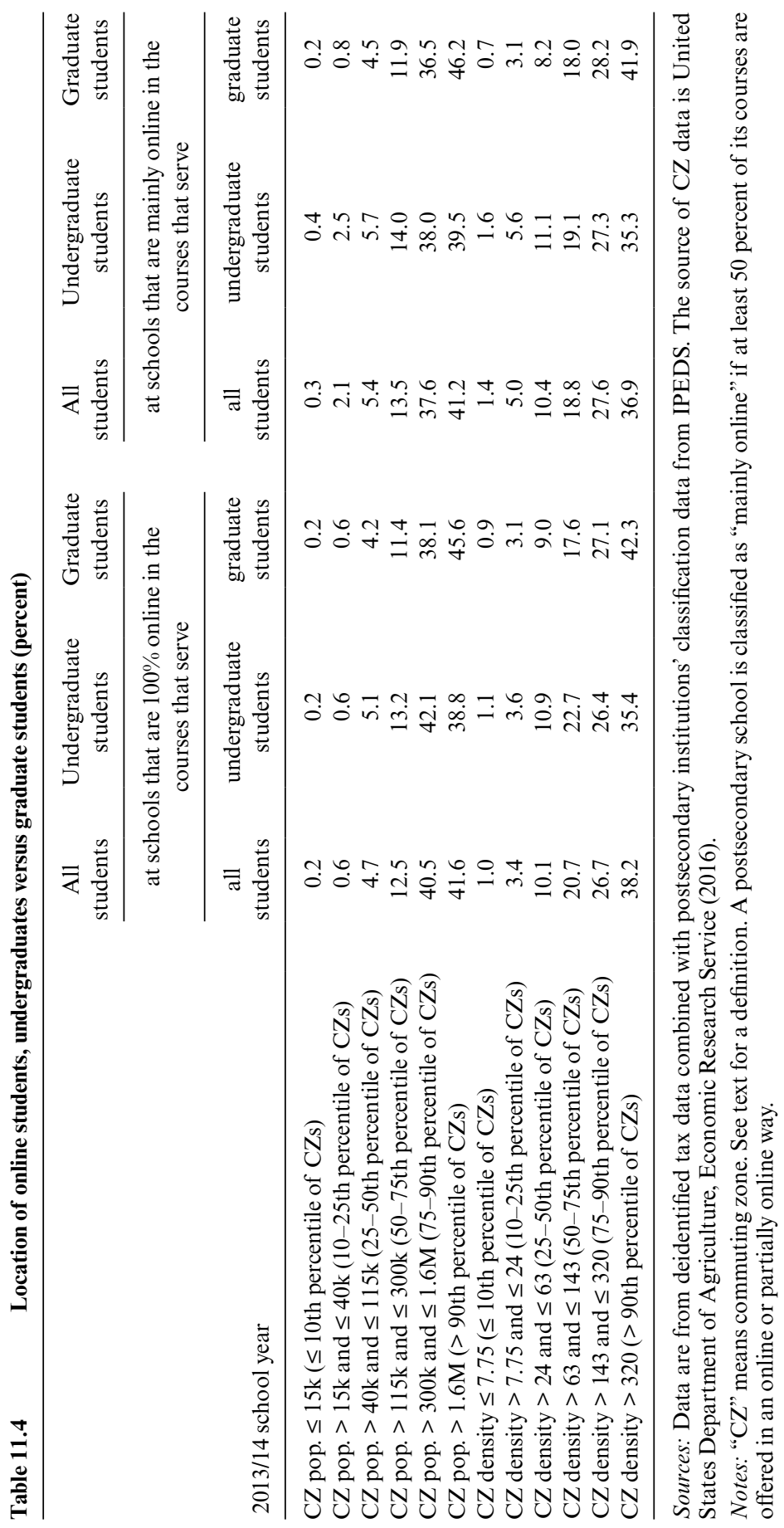




\begin{tabular}{lrrrr}
\hline & \multicolumn{4}{c}{$\begin{array}{c}2013 / 14 \text { students at postsecondary } \\
\text { schools that are }\end{array}$} \\
\cline { 2 - 5 } & $\begin{array}{r}100 \% \\
\text { online }\end{array}$ & $\begin{array}{c}\text { mainly } \\
\text { online }\end{array}$ & $\begin{array}{c}\text { hardly } \\
\text { online }\end{array}$ & $\begin{array}{c}\text { hardly online } \\
\text { and nonselective }\end{array}$ \\
\hline Public, four-year or above & 1.95 & 10.23 & 34.06 & 9.24 \\
Private not-for-profit, four-year or above & 21.03 & 44.15 & 33.17 & 4.23 \\
Private for-profit, four-year or above & 76.80 & 37.72 & 7.38 & 4.81 \\
Public, two-year & 0.02 & 6.67 & 13.74 & 45.53 \\
Private not-for-profit, two-year & 0.00 & 0.10 & 0.62 & 0.98 \\
Private for-profit, two-year & 0.09 & 0.84 & 5.99 & 16.87 \\
Public, less than two-year & 0.03 & 0.03 & 0.52 & 1.74 \\
Private not-for-profit, less than two-year & 0.00 & 0.00 & 0.14 & 0.40 \\
Private for-profit, less than two-year & 0.08 & 0.27 & 4.39 & 16.01 \\
\hline
\end{tabular}

Source: Data are from deidentified tax data combined with postsecondary institutions' classification data from IPEDS.

Notes: A postsecondary school is classified as "mainly online" if at least 50 percent of its courses are offered in an online or partially online way. A school is classified as "hardly online" if fewer than 10 percent of its courses are offered in an online or partially online way. Courses that serve "all students" are considered. A school is "nonselective" if any student with a high school diploma or GED may enroll in undergraduate classes or any student with a baccalaureate degree may enroll in graduate classes.

who attend institutions that are hardly online and nonselective. Among these students, 45.5 percent attend public two-year schools. For-profit two-year and less-than-two-year schools account for, respectively, 16.9 percent and 16.0 percent of such students. Only 4.8 percent of students who attend a school that is hardly online and nonselective attend an institution that grants at least a baccalaureate degree.

The contrasting statistics are surprising because, as mentioned previously, online nonselective schools appear to be competing for the same students as brick-and-mortar nonselective schools (Deming, Lovenheim, and Patterson, forthcoming). Moreover, students who attend nonselective schools tend to be only marginally prepared for college and must often take remedial courses before beginning college-level work. ${ }^{19}$ Thus, it is not obvious that a baccalaureate-granting institution is an appropriate fit for them. Also, table 11.1 gives us little reason to think that all online students are the "cream of the crop" of students who attend nonselective institutions. After all, most of them are still short of a baccalaureate degree (that is, still pursuing undergraduate education) even though they are in their midthirties. Furthermore, table 11.6 shows that it is not merely online graduate students who are almost exclusively in schools that grant at least the baccalaureate. Online undergraduate students are almost entirely in four-year-or-more schools, too.

19. See Long and Boatman (2013). 


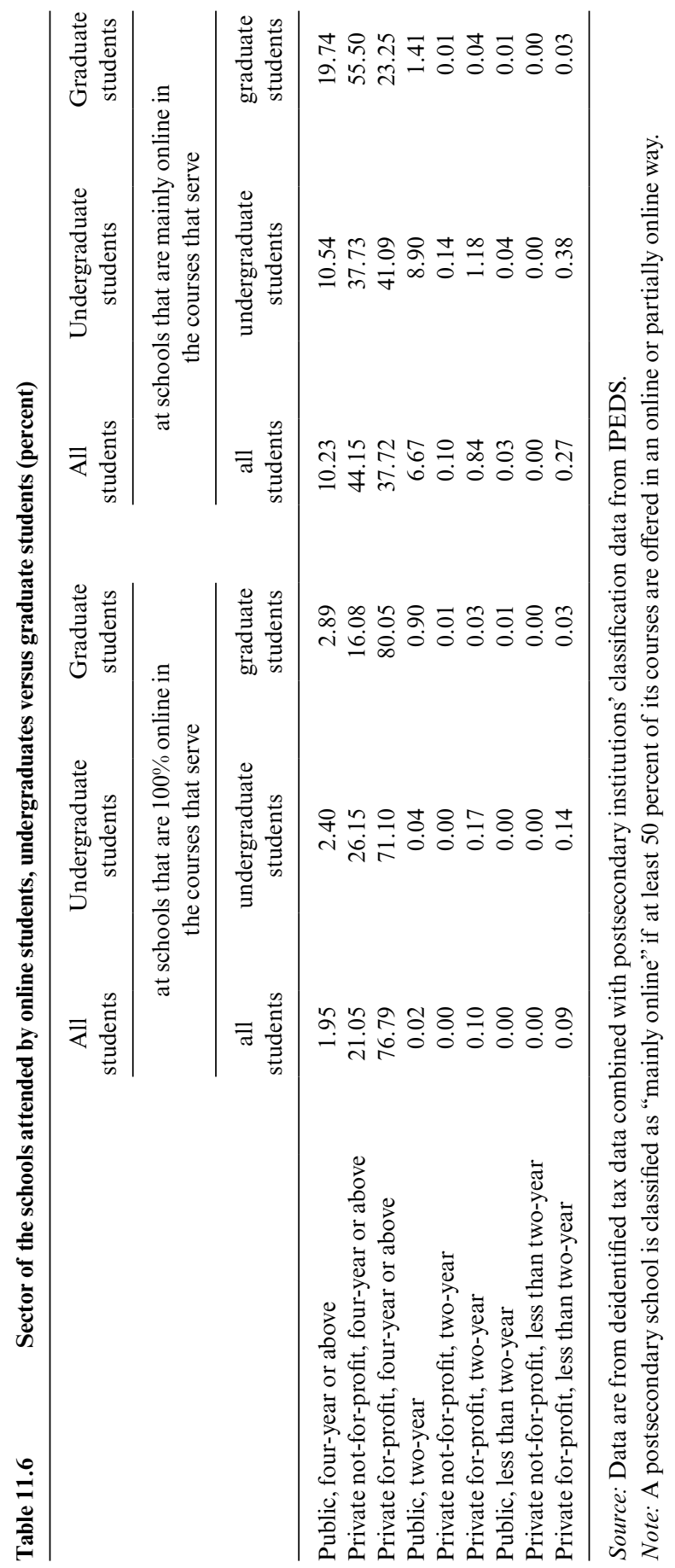


Because the typical online student is in her midthirties, data on test scores and grades at the end of high school are often unavailable for her birth cohort. However, in other work (Hoxby 2015), I find little difference in endof-high-school achievement between thirty-two-year-old students attending online nonselective and in-person nonselective schools in 2013. All this suggests that the same student is more likely to enroll in a four-year program if she attends online than if she attends in person. If online students complete their degree programs and learn a lot in them, it may be good that they attempted more ambitious degree programs. On the other hand, if they find themselves unable to learn the material, they might have been better off attempting a less ambitious degree program but completing it successfully. We cannot know without examining returns to education, so the contrast between online and in-person degree programs is an important reason to estimate ROIs.

\subsubsection{How Long Are Online Students' Enrollment Episodes?}

Sixty-one percent of online education is attributable to students with a single enrollment episode, 28 percent to students with two episodes, and 11 percent to students with three or more episodes. In order to avoid having an individual's experience counted more than once in what follows, I focus on the first enrollment episode. However, since multiple enrollment episodes are uncommon, the results are very similar if I choose one episode at random from each person's episodes, choose the most recent episode, or use all the episodes.

Figures 11.4 and 11.5 are histograms showing the length of the first enrollment episode for students who begin that enrollment episode at a school that is, respectively, exclusively online or mainly online. Note that if a student begins at a school that is exclusively online but later-in the same enrollment episode-switches to a school that is mainly online, the student is categorized as exclusively online for these histograms. The reverse is also true for switches from mainly to exclusively online. ${ }^{20}$

It is important to recall that an episode of length one (one calendar year) usually corresponds to less than one school year, an episode of length two usually corresponds to one school year, an episode of length three usually corresponds to two school years, and so on.

Figures 11.4 and 11.5 show that the lengths of exclusively online and mainly online enrollment episodes are distributed similarly. For both types of enrollment, the modal length of an episode is one calendar year or (probably) less than a single school year: these episodes represent 38 percent of episodes that are exclusively online and 50 percent of episodes that

20. Because the figures will show episode length to be similar across the two types of enrollment, the histograms would hardly change if I were to alter this method of categorization. 


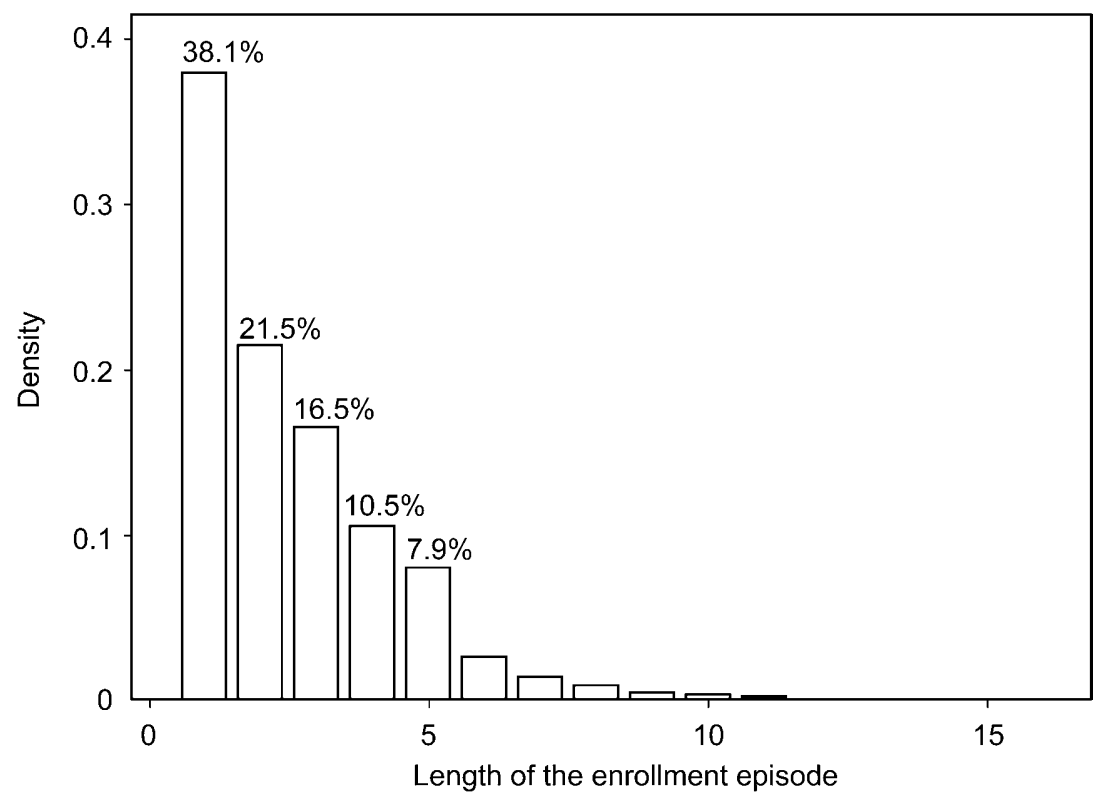

Fig. 11.4 Length of enrollment episodes that are exclusively online

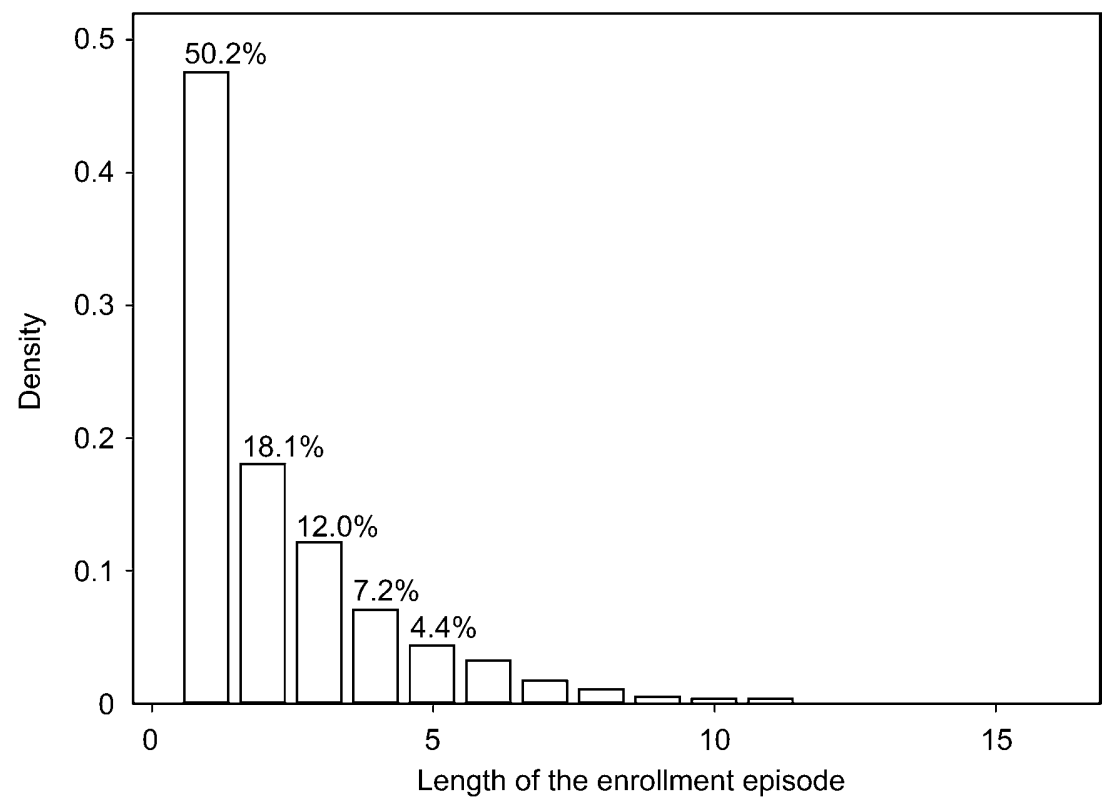

Fig. 11.5 Length of enrollment episodes that are mainly online 
are mainly online. The next most common length is two calendar years or (probably) one school year: 22 percent of episodes that are exclusively online and 18 percent of episodes that are mainly online. For episodes that begin in exclusively online schools, the median length is 2 and the mean length is 2.5 . The median is 1 and mean is 2.4 among episodes that begin in mainly online schools. Episodes of five or more calendar years, which are most likely to constitute a complete baccalaureate education, are rare: they constitute only 7.9 percent of episodes that begin at exclusively online schools and only 4.4 percent of episodes that begin at mainly online schools.

The preponderance of short enrollment episodes is striking because most online students are undergraduates and nearly all of them attend institutions that grant the baccalaureate degree at least. There are several possible interpretations. First, the vast majority of undergraduates could be attempting only to obtain a certificate or associate's degree even though their school is (more in theory than in practice) a baccalaureate degree-granting school. Second, students may be dropping out part of the way into a degree program (which may or may not be baccalaureate). Third, some of the students could have completed part of their postsecondary education prior to 1999. If so, they might only need a couple of years to complete their baccalaureate degree, especially if the online institutions are generous in allowing the transfer of credits from other institutions.

In the tax data, it is difficult to distinguish between these different explanations. However, the dropping-out explanation is indicated by IPEDS data on graduation rates. At exclusively and mainly online schools, only 22 percent of students complete the degree program in which they are enrolled within 150 percent of the normal time to degree completion. These statistics include students in all degree programs. Among these institutions' students who classify themselves as baccalaureate degree-seeking, only 2 percent complete a baccalaureate degree within six years. Another 14 percent complete some program such as a certificate or an associate's degree. ${ }^{21}$

21. Author's calculations based on IPEDS 2014 (the most recent) data. These contain graduation rates for students who commenced enrollment in 2008. Unfortunately, a good share of exclusively or mainly online postsecondary institutions did not report graduation rate data to IPEDS. In some cases, this is because the institution was so young in 2008. In other cases, the data are simply missing. The IPEDS degree completion rates are roughly consistent with the Beginning Postsecondary Students (BPS, 2004 and 2012 cohorts) longitudinal data. However, the BPS samples are even less representative than IPEDS. Given the size of BPS samples (approximately 16,700 students for the 2004 cohort, for instance), it is not possible to make the data, even with sampling weights, representative of a sector that accounts for a small share of enrollment, as the online postsecondary sector does. Moreover, the 2004 cohort only contains students who began their education before the 50 percent rule was dropped, so the data could not possibly describe the exclusively online sector. The most recent data available on the 2012 cohort is from 2014, when they could not be expected to have completed a baccalaureate degree. However, a good share of the online 2012 cohort has already experienced a gap in their enrollment. 


\begin{tabular}{|c|c|c|c|c|}
\hline & \multicolumn{4}{|c|}{$\begin{array}{l}\text { 2013/14 students at postsecondary } \\
\text { schools that are }\end{array}$} \\
\hline & $\begin{array}{l}100 \% \\
\text { online }\end{array}$ & $\begin{array}{l}\text { mainly } \\
\text { online }\end{array}$ & $\begin{array}{l}\text { hardly } \\
\text { online }\end{array}$ & $\begin{array}{l}\text { hardly online } \\
\text { and nonselective }\end{array}$ \\
\hline Instructional spending per FTE student & 2,334 & 3,821 & 12,879 & 5,426 \\
\hline \multicolumn{5}{|l|}{ Academic support and student service spending per } \\
\hline FTE student & 2,469 & 3,318 & 6,491 & 2,740 \\
\hline Institution support per FTE student & 3,522 & 3,241 & 4,686 & 2,981 \\
\hline Tuition paid & 6,131 & 6,758 & 11,930 & 4,919 \\
\hline Total grants and scholarships received (includes zeros) & 1,864 & 2,315 & 5,051 & 2,106 \\
\hline Pell grants received (includes zeros) & 1,529 & 1,458 & 2,046 & 2,489 \\
\hline Other federal grants received (includes zeros) & 69 & 89 & 198 & 117 \\
\hline State and local grants received (includes zeros) & 73 & 138 & 294 & 188 \\
\hline Institutional grants received (includes zeros) & 183 & 632 & 1,923 & 175 \\
\hline $\begin{array}{l}\text { Amount of nonrefundable education credits taken } \\
\text { (includes zeros) }\end{array}$ & 1,369 & 1,407 & 1,443 & 1,247 \\
\hline Amount of refundable American Opportunity Tax & & & & \\
\hline Credit taken (includes zeros, 2008 onward only) & 619 & 729 & 851 & 789 \\
\hline $\begin{array}{l}\text { Amount of tuition and fees tax deduction taken } \\
\text { (includes zeros) }\end{array}$ & 24 & 16 & 7 & 3 \\
\hline $\begin{array}{l}\text { Federal loans taken, undergraduates only (includes } \\
\text { zeros) }\end{array}$ & 4,228 & 5,075 & 4,424 & 4,259 \\
\hline Published undergraduate tuition and fees & 9,548 & 14,193 & 18,841 & 6,483 \\
\hline Published graduate tuition and fees & 9,730 & 10,890 & 17,354 & 11,542 \\
\hline Default rate in first fiscal year (\%) & 12.5 & 10.3 & 7.5 & 15.3 \\
\hline
\end{tabular}

Source: Data are from deidentified tax data combined with postsecondary institutions' classification data from IPEDS.

Notes: A postsecondary school is classified as "mainly online" if at least 50 percent of its courses are offered in an online or partially online way. A school is classified as "hardly online" if fewer than 10 percent of its courses are offered in an online or partially online way. Courses that serve "all students" are considered. A school is "nonselective" if any student with a high school diploma or GED may enroll in undergraduate classes or any student with a baccalaureate degree may enroll in graduate classes.

\subsubsection{How Much Does Online Postsecondary Education Cost and Who Pays for It?}

In this subsection, I use IPEDS data to show how much instructional and other educational spending online students experience. I use both IPEDS and tax data to show who pays for this spending: the student himself, federal taxpayers, and so forth.

Table 11.7 shows statistics for all students, and table 11.8 shows them separately for undergraduate and graduate students. The data in the tables are for the 2013/14 school year. ${ }^{22}$ Because the tax data are associated with

22. The tax deduction for tuition and fees is an exception (see below). 


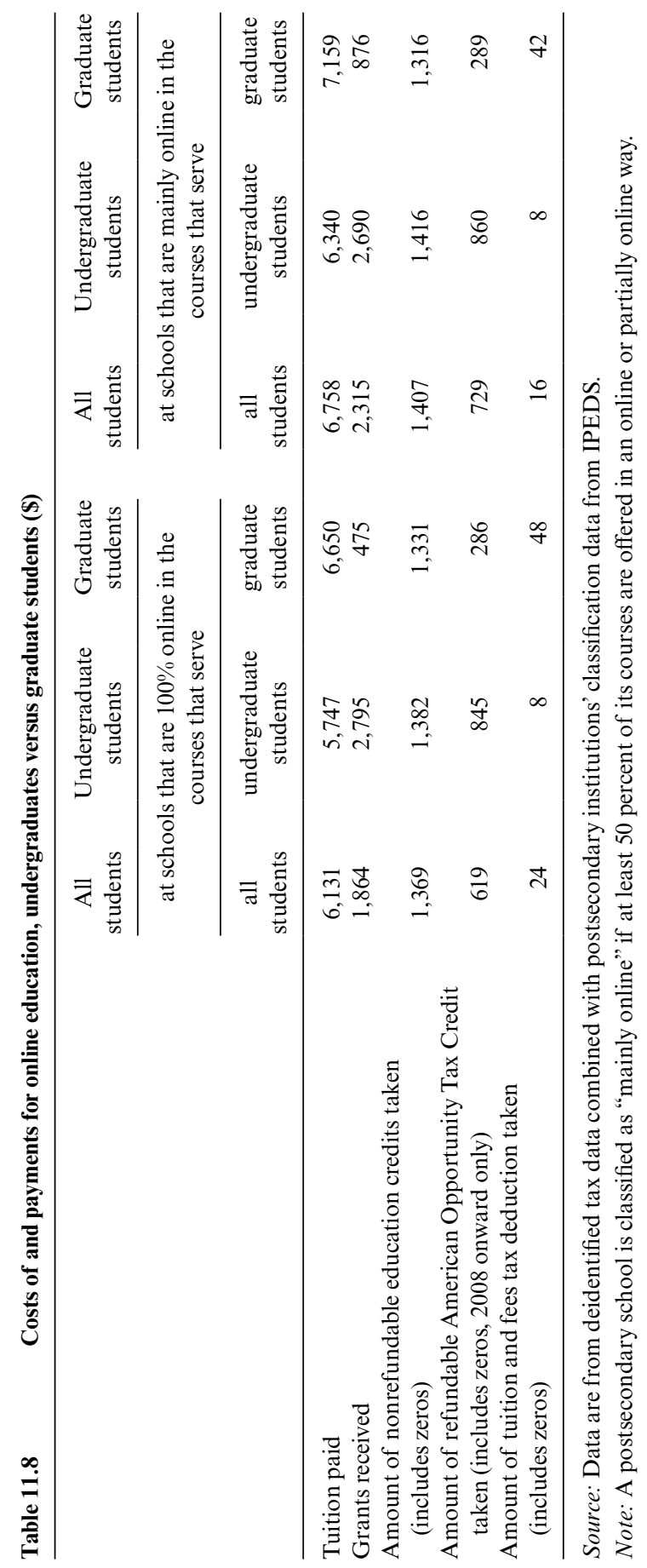

You are reading copyrighted material published by University of Chicago Press. 
calendar years and because many enrollment episodes are so short that the calendar year represents less than a school year, I have adjusted the variables derived from tax data to make them as representative as possible of the 2013/14 school year. ${ }^{23}$ For various reasons, readers should not expect payments, when totaled, to equal one of the two spending variables. ${ }^{24}$

IPEDS suggests that four types of spending are particularly relevant to students: an institution's spending on instruction, its spending on academic support, ${ }^{25}$ its spending on student services, ${ }^{26}$ and its spending on institutional support. ${ }^{27}$ Together, these four categories make up "core" spending, which is intended to include costs associated with educating a student but to exclude spending on research, public service, maintenance and operations, construction, feeding students, and housing students. Since online schools organize the student experience differently than brick-and-mortar ones, it is useful to see student-related spending separately by instruction and the remainder of core spending.

Exclusively online schools spend \$2,334 per full-time equivalent (FTE) student on instruction, but mainly online schools spend $\$ 3,821$ or 64 percent more. Schools that are hardly online and nonselective spend much more: $\$ 5,426$ (132 percent more than exclusively online schools and 42 percent more than mainly online schools). These numbers suggest that exclusively and mainly online schools are achieving substantial cost savings on instruction. However, these savings do not carry over to other per FTE core spend-

23. Specifically, I compute the ratio of (numerator) a student's school's published tuition and fees for the spring term of the 2012/13 school year and the fall term of the 2013/14 school year to (denominator) the sum of a person's payments and grants in 2013 calendar year. This ratio indicates the percentage of a school year that the tax-based variables likely represent. I multiply students' tax credits and deductions by this ratio to make those variables comparable to all the other variables in the tables, which are based on school years. For instance, if a student enrolled in an online school in the fall of 2013 but had no enrollment in the spring of 2013, his tax credits and deductions would reflect only half of a school year. To get a full school year's worth of credits and deductions, we would need to multiply by the ratio, which would be about 2 in his case.

24. First, neither instructional nor core spending are the total spending on a student's education. The ratio of core to total spending varies considerably by institution. Some institutions' spending is reported imprecisely because the institution must allocate overhead among its activities, which may include activities other than students' education. IPEDS does not force schools' spending, "saving," and other disbursements to equal their revenues. As a result, some institutions' spending is difficult to reconcile with their revenue. IPEDS (school year) and tax (calendar year) data are poorly aligned, even after the adjustments described in the previous footnote.

25. Academic support includes expenses that support instruction such as libraries, audiovisual services, academic administration, curriculum development, and so on.

26. Student support includes expenses for admissions, registrar activities, supplemental instruction, and student records. It also includes activities that contribute to students' development outside the formal instructional program. Examples of the latter would be student newspapers, curricular clubs (science club, French language society), and student government.

27. Institutional support includes expenses for the day-to-day operations including administrative services, central activities concerned with management and planning, legal, and fiscal operations, space management, human resources, records, purchasing, and so on. 
ing, which is $\$ 5,991$ at exclusively online schools, $\$ 6,559$ at mainly online schools, and \$5,721 at hardly online nonselective schools. Overall, the similar or somewhat greater spending on other core activities are not what one might expect if one thinks of online schools providing instruction but not other parts of a brick-and-mortar student experience: libraries, student newspapers, curricular clubs, in-person student advising, and the like. It must be that online schools provide instruction inexpensively but spend disproportionately (relative to instructional spending) on curriculum development, administrative services, and legal and fiscal operations.

Toward the bottom of table 11.7, there are rows that show schools' published tuition and fees for a full-time, full-year undergraduate or graduate student. It is useful to compare these numbers to core spending. For instance, exclusively online schools' core spending is $\$ 8,325$, and their tuition and fees are $\$ 9,548$ (undergraduates) and $\$ 9,730$ (graduates). Given their ratio of undergraduate to graduate students (table 11.1), they have about $\$ 1,296$ from tuition and fees to cover noncore costs and for profits. Mainly online schools' core spending is $\$ 10,480$, and their tuition and fees are $\$ 14,193$ (undergraduates) and $\$ 10,890$ (graduates). They have an average of $\$ 2,960$ dollars to cover noncore costs and for profits. Finally, the core spending of hardly online and nonselective schools is $\$ 11,147$, while their tuition and fees are $\$ 6,483$ (undergraduate) and $\$ 11,542$ (graduate). In other words, many of these schools cannot meet their expenses with tuition revenue. The difference is made up by state and local government appropriations that effectively subsidize tuition. (Recall from table 11.5 that 56.5 percent of these students attend public schools.) For the perspective of current students, however, hardly online nonselective schools offer generous spending per dollar of tuition, relative to online schools.

Now consider who pays for the spending on students' education. Note that the following figures reflect what is actually paid, and not all students are full-time, full-year students. Thus, we should not expect these payments to reflect FTEs as the numbers in the previous paragraphs did.

The first noteworthy result in table 11.7 is that students themselves pay more for their education at online schools than do students who attend schools that are hardly online and nonselective. Students at exclusively online schools paid an average of $\$ 6,131$ in tuition, and their counterparts at mainly online schools paid $\$ 6,758$. In comparison, students at schools that are hardly online and nonselective paid an average of only $\$ 4,919 .{ }^{28}$ These differences in tuition paid are mainly due to differences in published tuition and fees, not due to differences in grants (see below). In particular, the subsidized tuition at public hardly online nonselective schools plays the key role.

28. Tuition paid at schools that are hardly online but selective is of course much higher since such schools include the most resource-rich schools in the United States. They spend an order of magnitude more per student than do nonselective schools. See Hoxby and Avery (2013). 
The second noteworthy result is that federal taxpayers would foot between 36 and 44 percent of the total cost of online education, even if students were to repay their federal loans fully. If they were to repay only 50 percent of their loans, federal taxpayers would fund 60 to 69 percent of the cost of online education. This heavy dependence on federal taxpayers arises because online students not only receive federal grants of around $\$ 1,600$ per year, they also make disproportionate use of the federal tax credits and deductions for tuition and fees. The average student who is attending an exclusively online school takes a nonrefundable credit of $\$ 1,472$ and a refundable credit of $\$ 867$. The average student attending a mainly online school takes a nonrefundable credit of $\$ 1,492$ and a refundable credit of $\$ 981$. These are close to the maximum possible credits of $\$ 1,500$ (nonrefundable) and $\$ 1,000$ (refundable). These amounts are about 20 percent greater than those for the average student at hardly online nonselective schools. Online students also make disproportionate use of the tax deduction for tuition and fees. Compared to students at hardly online nonselective schools, exclusively online students take eight times the deduction and mainly online students take more than five times the deduction. All of the deduction amounts may seem small, but this is not because the deduction that students take, if they take it, is small. Rather, those who take it take close to the maximum possible deduction $(\$ 4,000)$, but in recent years the credits have been more generous than the deduction for most students. Thus, the apparently small amounts reflect students choosing a tax credit over the deduction. (A student cannot simultaneously take a credit and a deduction. $)^{29}$

A third noteworthy finding is that other payments are fairly similar across schools that were exclusively online, mainly online, and hardly online and nonselective. For instance, grants and scholarships paid for an average of about $\$ 2,100$ in both online and in-person schools. ${ }^{30}$ The average student's federal loan was almost identical for students attending schools that were exclusively online $(\$ 4,228)$ and hardly online and nonselective $(\$ 4,259)$. Students at institutions that were mainly online had higher federal loans that averaged $\$ 5,075$.

At this point, it is worthwhile taking a step back to assess online schools'

29. The tax deduction for tuition and fees is an "above-the-line" deduction, so a person need not itemize to take it. Its maximum possible value is $\$ 4,000$ times the tax filer's tax rate-for instance, $\$ 1,200$ for a taxpayer with a 30 percent rate. The Opportunity Tax Credit is a temporary credit with a maximum possible value of $\$ 2,500$. The Hope Tax Credit and Tax Credit for Lifelong Learning are permanent credits with maximum possible values of $\$ 1,800$ and $\$ 2,000$, respectively. Because the tax deduction and credits have different eligibility criteria, some individuals maximize the tax expenditure on their education by taking the deduction, even if a credit would superficially appear to be more generous. If the Opportunity Tax Credit is not renewed or made permanent, the tax deduction will again be more used because it is more comparable in generosity to the Hope Tax Credit and Tax Credit for Lifelong Learning.

30. The small difference in the amount of Pell grants, in favor of hardly online students, is due to online students having incomes that are too high for eligibility. 
costs and payments relative to what we might have expected based on the debate described in the introduction and based on the previous literature. Online schools do spend considerably less on instruction per FTE student, but they spend more on other core activities: academic support, student services, and institutional support. As a result, exclusively online schools are only 25 percent and mainly online schools are only 7 percent less costly than comparably selective schools in which the student experience is in person. These seem like modest cost savings relative to what was promised by supporters of online education - represented, for instance, by the quotation in the introduction. They are especially modest when one considers that exclusively online schools do not even attempt to replicate many dimensions of the in-person experience: libraries, laboratories, academic clubs, student music and drama, and so on. Furthermore, it is not obvious that online students would be glad to learn that all of the cost savings at their schools are achieved by spending less on instruction. Since instruction (and not the central office) is what they experience, one would presumably need to argue that the comparatively large amount spent on institutional support (administrative services, central management and planning, legal and fiscal operations, human resources, records, purchasing, etc.) is truly a modern form of instructional spending whereby central activities efficiently substitute for individual instructors.

Second, payments alone cannot explain why students are shifting to online enrollment and away from in-person enrollment at similarly nonselective schools. Online students are paying 25 to 37 percent more for an education that costs less to produce. Thus, we should consider other reasons why students may prefer online schools: the flexibility of course timing, the lack of a commute to and from campus, rationed classes at in-person schools, and so on. We should also consider some less positive reasons: lax academic standards, greater opportunities for cheating, and marketing that is more likely to promise exaggerated results (United States General Accountability Office 2010, 2011). It is difficult to separate these explanations using the data in this chapter. However, in Hoxby (2014), I found little or no evidence that students were engaging in online education because such schools offered advanced or exotic courses not available at brick-and-mortar, nonselective schools. Course-taking at online schools is highly concentrated in basic courses that are offered in nearly all nonselective postsecondary institutions: algebra, elementary accounting, data entry, reading comprehension, composition, and introductory courses in the social sciences.

\subsection{Earnings before and after Online Enrollment}

In this section, I use figures to illustrate how students' earnings evolve before and after an episode of enrollment at an institution that is exclusively 


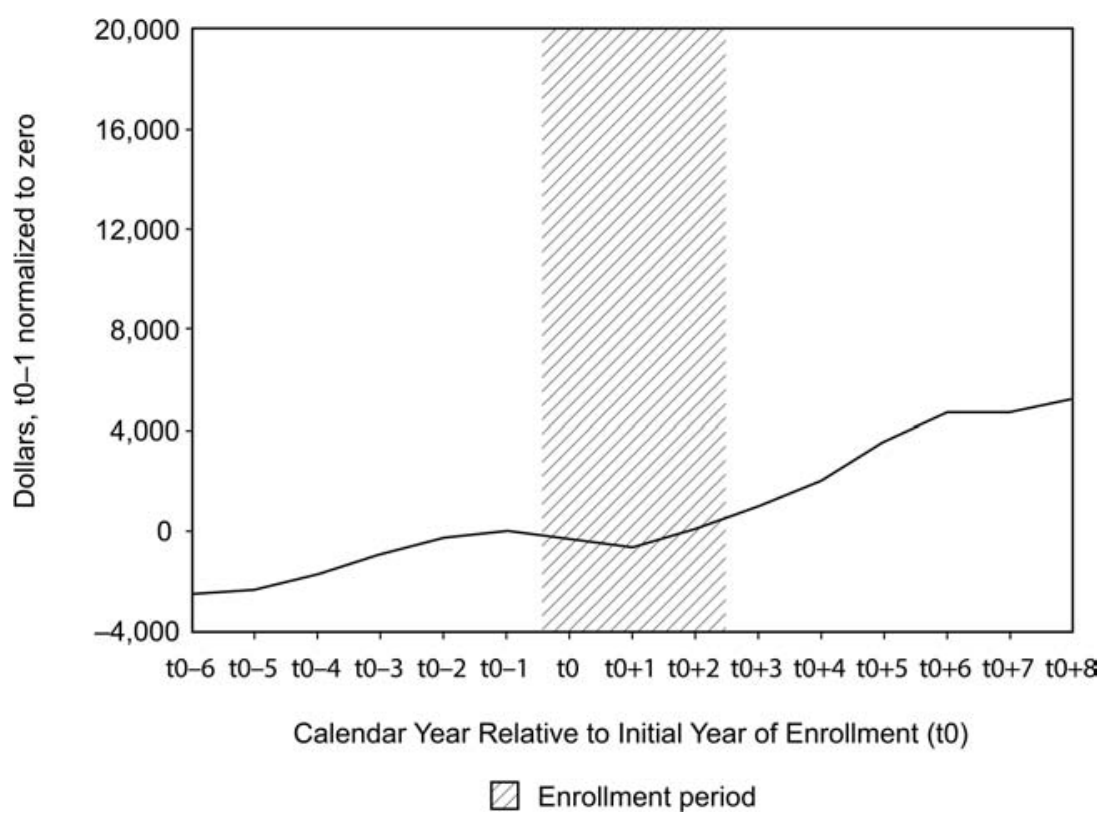

Fig. 11.6 Wages before, during, and after a three-calendar-year episode of postsecondary enrollment that is exclusively online

or mainly online. While these figures do not provide us with ROI estimates, they are designed to make transparent the data behind the estimates.

It is worthwhile describing the first of these figures, figure 11.6, carefully since all of the figures that follow have a similar basis. Figure 11.6 shows wage and salary earnings for all students who enrolled in exclusively online schools and whose enrollment episode lasted three calendar years (most likely two school years). I start with episodes that last three calendar years because they are fairly common (17 percent of exclusively online and 12 percent of mainly online) and because they are long enough for a person plausibly to earn an associate's degree, earn a master's degree, or complete a baccalaureate degree if the person already had a significant number of undergraduate credits when he enrolled. Rather than show raw wage and salary earnings for such students, I partial out calendar-year indicators and a quadratic polynomial in the person's age.

$$
\begin{aligned}
y_{i t}= & \alpha+\beta_{t_{0}-6}+\beta_{t_{0}-5}+\ldots+\beta_{t_{0}-2}+\beta_{t_{0}}+\beta_{t_{0}+1}+\beta_{t_{0}+2}+\ldots+\beta_{t_{0}+6} \\
& +\gamma_{\text {calendar year } t}+\delta_{1} \text { age }_{i t}+\delta_{2} \text { age }_{i t}^{2}+\varepsilon_{i t} .
\end{aligned}
$$

The calendar-year fixed effects account for macroeconomic conditions, the price level, and changes in the online schools available each year. The qua- 
dratic in age accounts for smooth regularities in the relationship between age and earnings. ${ }^{31}$ What the figure shows, therefore, are the estimates of $\beta$, the coefficients on indicators for the years leading into the enrollment $\left(t_{0}-6\right.$, for instance), the year in which the episode begins $\left(t_{0}\right)$, and the years following the commencement of the episode $\left(t_{0}-6\right.$, for instance). Earnings are normalized to zero in year $t_{0}-1$.

Since the enrollment episode in figure 11.6 occurs over three calendar years, earnings in years $t_{0}, t_{0}+1$, and $t_{0}+2$ may be reduced directly because the student is spending his time studying instead of working. However, none of the other coefficients in $\beta$ are directly affected by enrollment. Rather the preenrollment coefficients give us a sense of what triggered the episode, while the postenrollment coefficients give us a sense of postenrollment gains.

Figure 11.6 shows that students who will be enrolled for three calendar years at exclusively online schools have earnings that are growing at a modest rate of about $\$ 504$ per year prior to enrolling. There is some sign of Ashenfelter's Dip: earnings growth between $t_{0}-2$ and $t_{0}-1$ is only $\$ 230$. Earnings fall during the period of enrollment $\left(t_{0}\right.$ through $\left.t_{0}+2\right)$, probably the direct effect of substituting study for work. ${ }^{32}$ However, the decline in earnings is small: several hundred dollars, not several thousand. This suggests that people continue to work much as before when they enroll in exclusively online education. They are certainly not discontinuing work altogether or halving their work time. In the calendar years that strictly postdate the enrollment episode $\left(t_{0}+3\right.$ through $\left.t_{0}+8\right)$, earnings grow at an average rate of $\$ 853$ a year, faster than preenrollment earnings.

Summing up, we see that three-calendar-year (probably two-school-year) episodes of exclusively online enrollment may lead to somewhat faster earnings growth. Countering this, society pays $\$ 23,985$ ( $\$ 7,995$ for each of three years) for the education in the episode. Out of this, the student himself pays $\$ 12,357$ ( $\$ 4,119$ for each of three years) if he eventually repays his loans in full. (The first year default rate is 12.5 percent.) In addition, the student earns slightly less while enrolled, but this change is so small that he can only be substituting out of work (and into study) to a very limited extent.

Figure 11.7 is exactly analogous to the previous figure except that it shows earnings for three-calendar-year episodes in schools that are mainly, rather than exclusively, online. Prior to enrollment, earnings are rising by an average of $\$ 716$ per year. There is a suggestion of Ashenfelter's Dip: earnings growth between $t_{0}-2$ and $t_{0}-1$ is only $\$ 513$. Earnings are lower during the period of enrollment, suggesting the substitution of studying for working.

31. Since age-earnings profiles can be well approximated by a quadratic, I obtain very similar figures if I use a cubic, quartic, or quintic in age. Such figures are available from the author. Moreover, the lack of additional explanatory power in polynomials beyond a quadratic motivates my use of the quadratic in formal ROI calculations (see below).

32. Notice that earnings are especially low in $t_{0}+1$, the only calendar year in which the person is probably enrolled for a full — as opposed to half — a school year. 


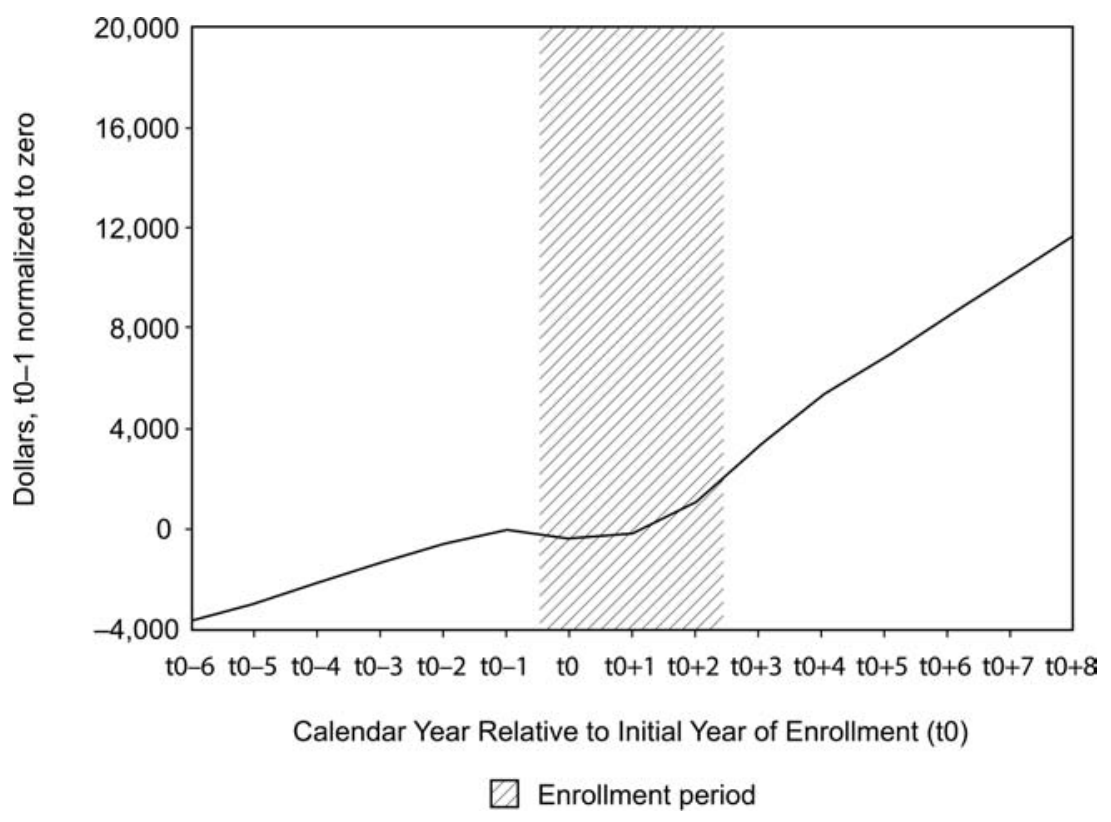

Fig. 11.7 Wages before, during, and after a three-calendar-year episode of postsecondary enrollment that is mainly online

Earnings grow by an average of $\$ 1,670$ per year in the calendar years that strictly postdate the enrollment episode.

In short, the three-calendar-year (probably two-school-year) episodes of mainly online enrollment may be triggered by mild Ashenfelter's Dips. After the enrollment episode ends, earnings growth is higher than in the preenrollment period. For this apparent improvement, society pays $\$ 27,219$ ( $\$ 9,073$ for each of three years). The student himself pays $\$ 13,818$ ( $\$ 4,606$ for each of three years) if he eventually repays his loans in full. (The first year default rate is 10.3 percent.) In addition, the student faces lower earnings while enrolled. However, figure 11.7 suggests that these opportunity costs are small — in hundreds rather than thousands per year. Such small opportunity costs suggest that people continue to work without much change, even when they are enrolled at mainly online schools.

Figures $11.8,11.9,11.10$, and 11.11 show earnings around exclusively online episodes with calendar-year lengths of one, two, four, and five years. Figures $11.12,11.13,11.14$, and 11.15 do the same for mainly online episodes. They can be summarized briefly as follows. Occasionally, there is evidence for an Ashenfelter's Dip (actually, a mere slowdown in earnings growth) just prior to the enrollment episode, but some figures show no such evidence and there are only mild slowdowns in the figures that do show it. Earnings fall during the enrollment episode, but they never fall enough to 


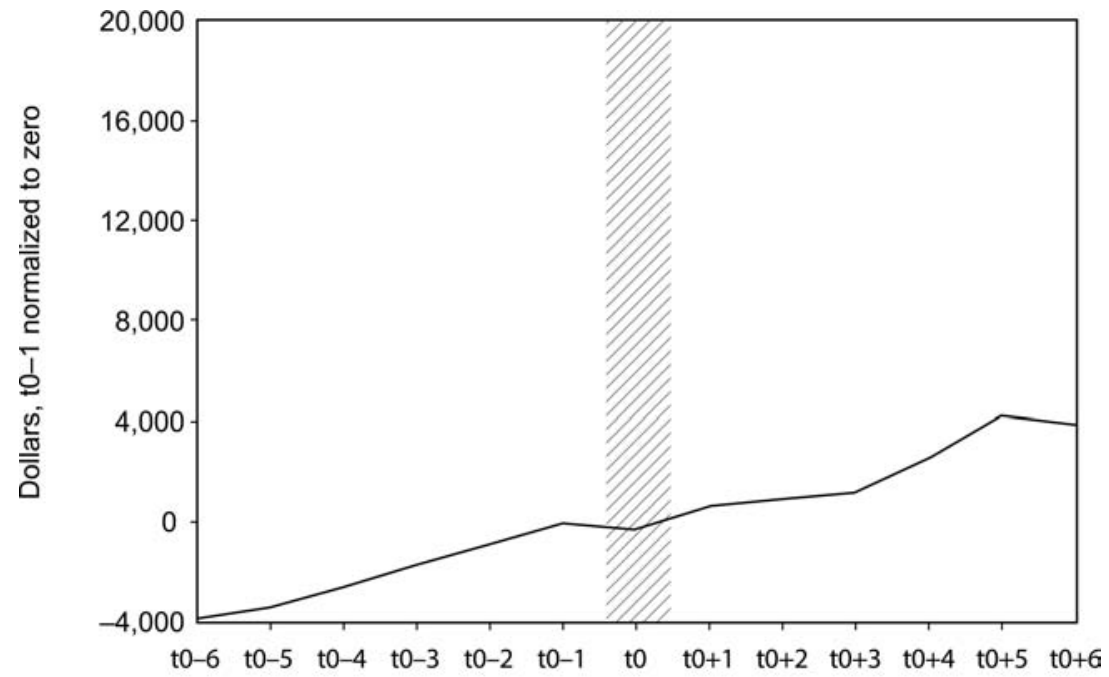

Calendar Year Relative to Initial Year of Enrollment (t0)

Enrollment period

Fig. 11.8 Wages before, during, and after a one-calendar-year episode of postsecondary enrollment that is exclusively online

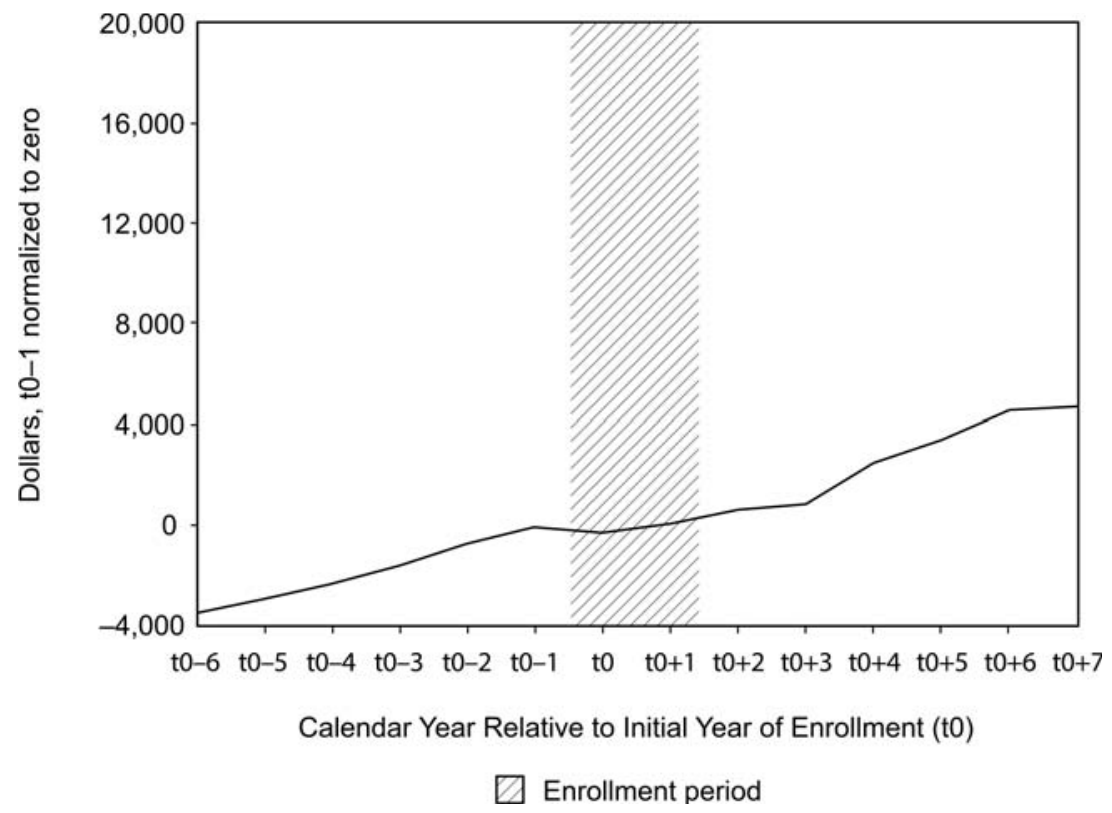

Fig. 11.9 Wages before, during, and after a two-calendar-year episode of postsecondary enrollment that is exclusively online 


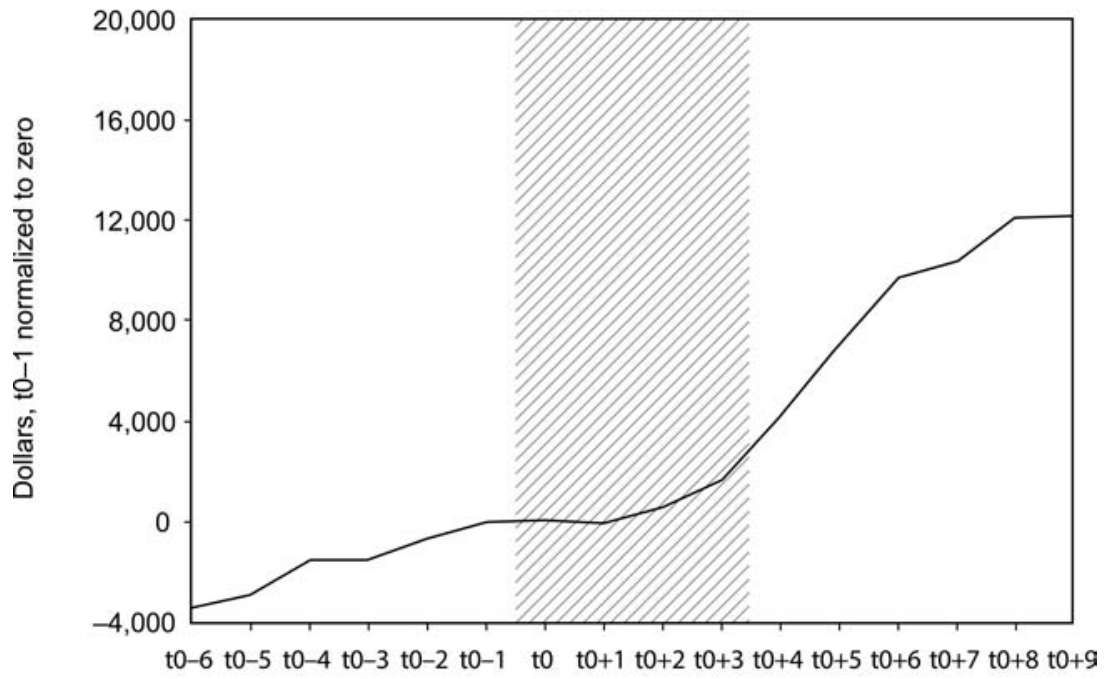

Calendar Year Relative to Initial Year of Enrollment (to)

$\square$ Enrollment period

Fig. 11.10 Wages before, during, and after a four-calendar-year episode of postsecondary enrollment that is exclusively online

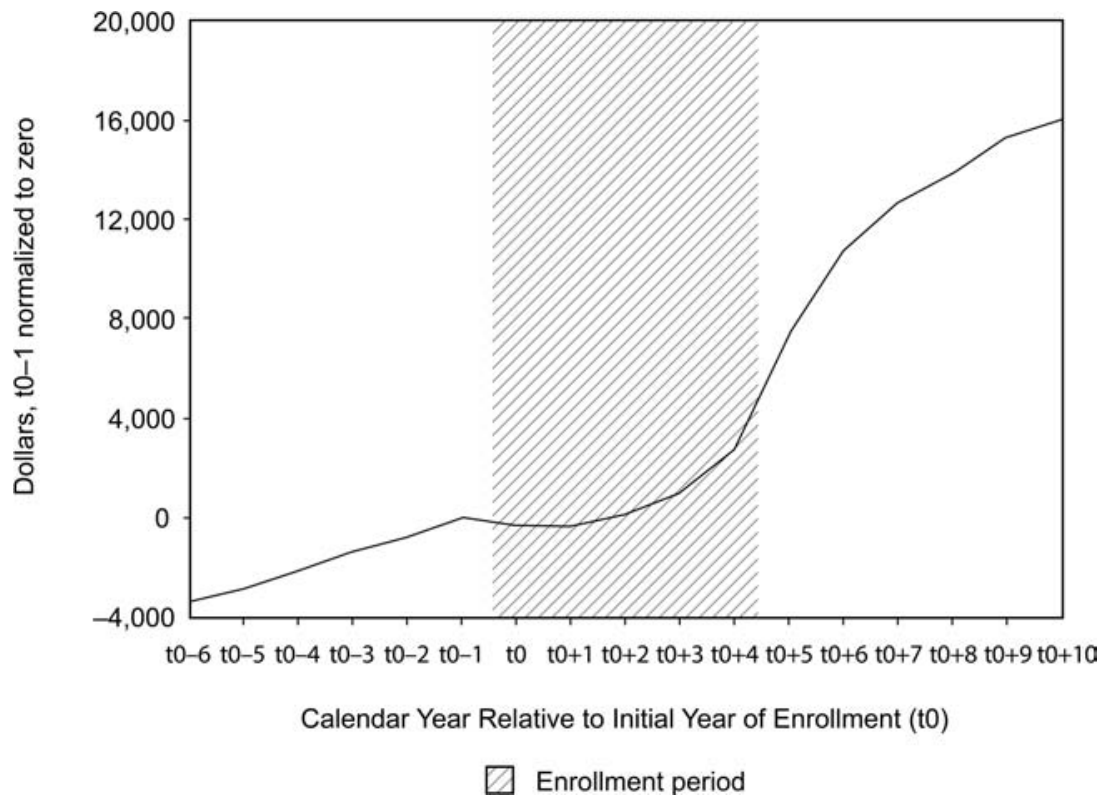

Fig. 11.11 Wages before, during, and after a five-calendar-year episode of postsecondary enrollment that is exclusively online 


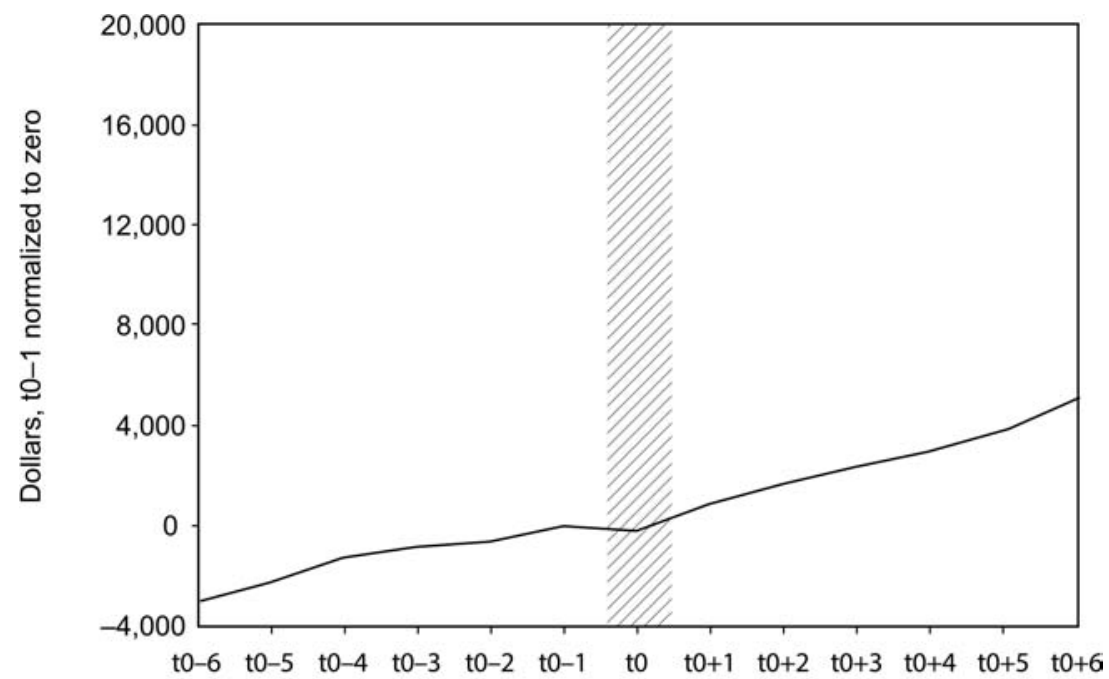

Calendar Year Relative to Initial Year of Enrollment (t0)

Enrollment period

Fig. 11.12 Wages before, during, and after a one-calendar-year episode of postsecondary enrollment that is mainly online

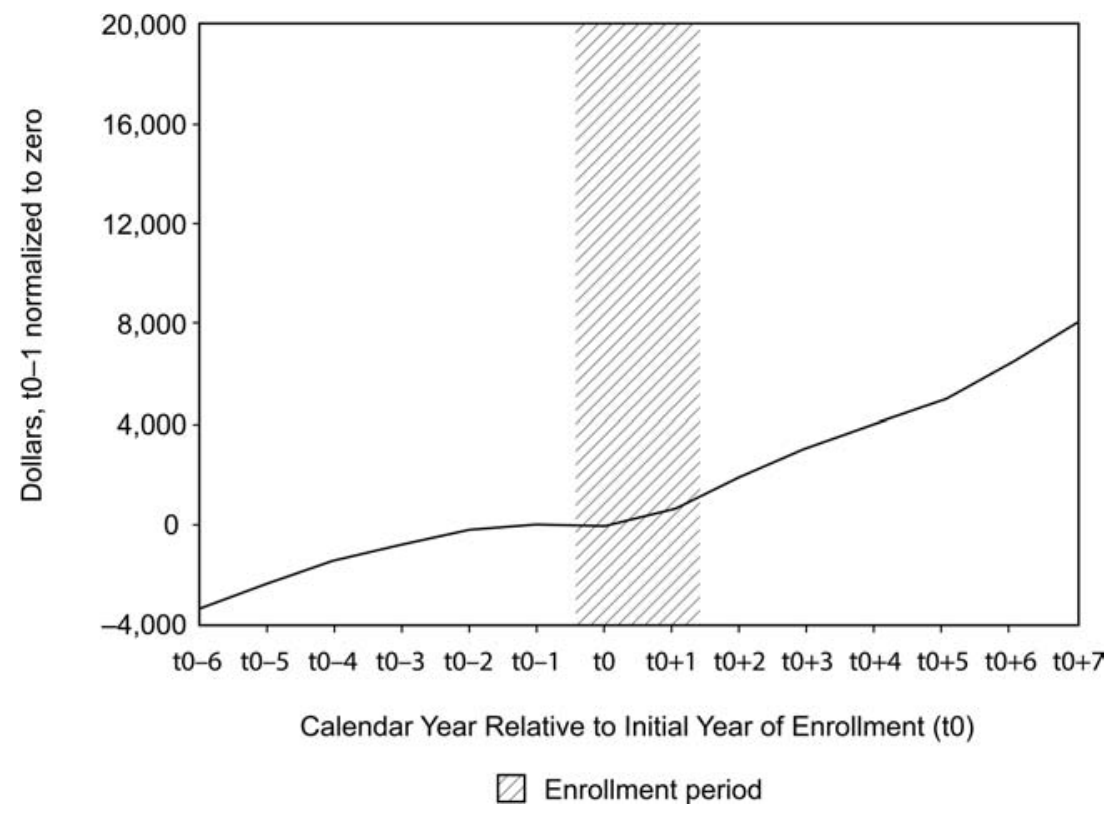

Fig. 11.13 Wages before, during, and after a two-calendar-year episode of postsecondary enrollment that is mainly online 


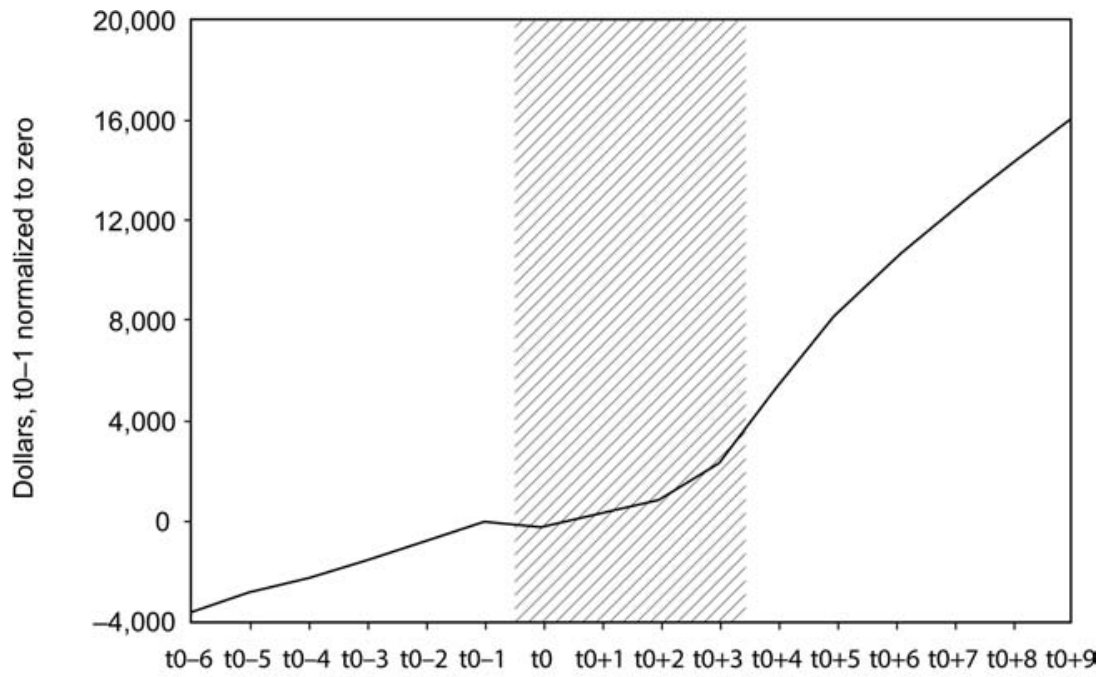

Calendar Year Relative to Initial Year of Enrollment (to)

Enrollment period

Fig. 11.14 Wages before, during, and after a four-calendar-year episode of postsecondary enrollment that is mainly online

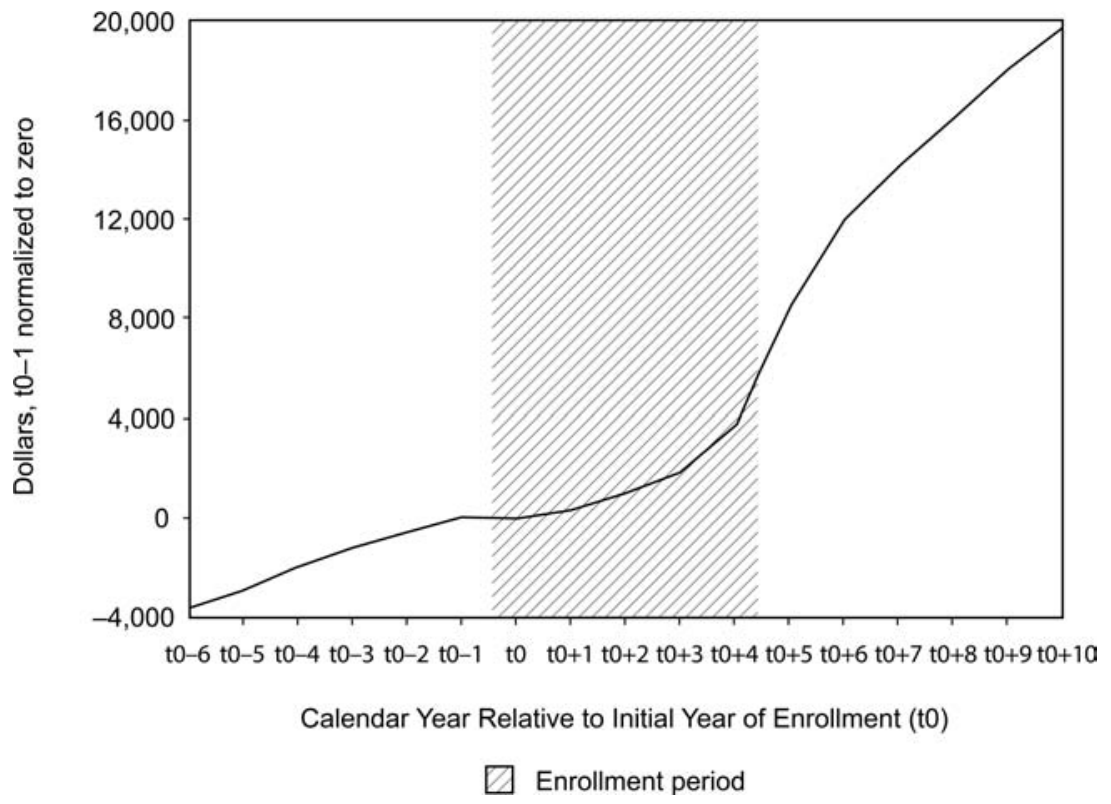

Fig. 11.15 Wages before, during, and after a five-calendar-year episode of postsecondary enrollment that is mainly online 
be consistent with students leaving work entirely or even cutting their work hours substantially. Annual earnings growth is higher after the enrollment episode than before enrollment commences. The shorter the episode the smaller the before-versus-after increase in annual earnings growth. Indeed, for the short episodes of one and two calendar years the before-versus-after increase in growth is very modest, just a few hundred dollars per year. These episodes are important because they account for 60 percent of exclusively online enrollment and 68 percent of mainly online enrollment. The beforeversus-after increase in earnings growth is most striking for episodes of five calendar years (probably four school years), but recall that such episodes are rare: 7.9 percent of exclusively online and 4.4 percent of mainly online enrollment.

One might consider several variants of the figures described above: figures for males only (since they have zero earnings less frequently than females), figures that include individual person fixed effects (to account for changing self-selection into online education over time), figures for graduate students only, and figures for undergraduate students only. Almost without exception, these variants generate figures (available from the author) that show patterns so similar to those already shown that it is hard to gain additional insights from them.

\subsection{An Empirical Strategy for Estimating Return on Investment to Online Education}

\subsubsection{The Regularities Observed So Far}

We have observed several regularities regarding earnings and online education. First, online education, though much more common than in the past, is still an uncommon way of pursuing postsecondary education. Thus, it is implausible that there is not selection into online education: it is unlikely to be a random choice. Second, most people who engage in online education are older than eighteen to twenty-four, the traditional age range for postsecondary enrollees. This, combined with the first observation, means that there is no obvious control group of people who are like the online students but who attend brick-and-mortar schools or who attend no postsecondary school at all. Third, in part because of their age, nearly all online students have earnings both before and after enrolling in online education. This is helpful empirically and is a feature that we usually lack when analyzing postsecondary students of traditional age. Fourth, although many subgroups of students show no sign of Ashenfelter's Dip prior to enrolling, at least some subgroups of students do appear to experience a mild Dip (really, just an earnings growth slowdown). The two most likely interpretations of such Dips are a deterioration in earnings opportunities at work (employer-driven events) or exogenous events (such as change in health) that cause earnings 
to slacken and also cause people to seek education. Regardless of which interpretation we adopt, an Ashenfelter's Dip makes it difficult to forecast what would have happened in the absence of online education because it suggests that at least some selection into online education is driven by changes in labor demand or labor supply. Sixth, during the years in which people are enrolled in online education, their earnings are slightly reduced, probably owing to their studying more. However, the reduction in earnings is so small that it is not consistent with students cutting their work hours more than slightly. Indeed, for some subgroups of students, opportunity costs appear to be negligible or even negative. We should not rule out negative opportunity costs as impossible because enrolling may give some students access to jobs that would otherwise be inaccessible to them. Finally, people pursue online education for varying periods, with everything from one to five calendar years being reasonably common. There is almost certainly considerable selection into these lengths: they are unlikely to be random.

Given these features of the data, the best empirical strategy to estimate returns would appear to be a within-person comparison of actual postenrollment earnings with (counterfactual) projected earnings based on preenrollment earnings. This is not an infallible strategy, but it does take advantage of the availability of preenrollment earnings data for the vast majority of online students. It is also a strategy that can accommodate enrollment episodes of differing lengths since a person's direct costs can be measured over however many years he is enrolled. Conveniently, opportunity costs can be computed using counterfactual earnings based on preenrollment data. Put another way, the only serious challenge to this empirical strategy is Ashenfelter's Dip, which makes projecting earnings difficult. However, this challenge can be somewhat overcome by bounding the estimates (see below).

\subsubsection{Alternative Empirical Strategies That Were Considered}

Other empirical strategies would not merely use a person's own earlier self to generate counterfactual earnings. They would specify a control group and use that group's earnings to generate counterfactual earnings. Given the abovementioned features of the data, however, all of the likely control groups would be prone to introduce selection bias, often of an unknown sign and magnitude. Compared to such bias, the challenges posed by Ashenfelter's Dip seem manageable if for no other reason than that we can sign and bound its consequences.

For instance, one possible control group would consist of people who were like the online enrollees in terms of age, sex, location, industry, and earnings (in the enrollees' preenrollment years), but who did not engage in online education. This is an enormous set of people, however, and selection into online education is rare and likely triggered by events that the controls would not have experienced. With so many potential controls and so little capacity to match on triggering events, it would be disturbingly ad hoc to choose con- 
trols even with sophisticated methods like synthetic controls. ${ }^{33}$ Moreover, the sign of the bias would be unclear: Would the controls be people whose experience was the same as the enrollees except that they lacked the initiative, motivation, and liquidity to pursue education? Or, would the controls be people who did not experience a triggering event or who had ways of responding to an event that were superior to online education? For instance, some controls might use a rich social network rather than online education to rebuild their earnings opportunities.

Another potential set of controls would be people similar to the online enrollees in terms of age, sex, location, industry, and earnings (in the enrollees' preenrollment years), but who enrolled in brick-and-mortar postsecondary education rather than online education. The difficulty here is that selection into online education is likely to be highly nonrandom. Since the timing of online classes is typically much more flexible, some part of the in-person versus online choice is probably due to factors such as whether a person is trying to simultaneously study and work or provide childcare. Some of the choice is probably due to the proximity of brick-and-mortar postsecondary institutions, but such proximity is distributed in a highly nonrandom way because brick-and-mortar institutions locate themselves near people who have a demand for education; the people who live close to brick-andmortar institutions are considerably more prone to demand postsecondary education than those who live far. ${ }^{34}$ Finally, some of the choice between online and brick-and-mortar education is probably due to the availability of high-speed internet, but the period of online education growth (from 2006 onward) was a period in which the only people without access to highspeed internet were truly rural, not merely people who lived in smaller or less densely populated labor markets. ${ }^{35}$ Summing up, people who choose brick-and-mortar education are probably (a) less likely to need flexibility while enrolled, which may indicate lower opportunity costs of interfering with work but also indicate fewer conflicts with family-related demands; (b) located in areas where the general demand for postsecondary education is higher, suggesting that employers' demand for skilled labor is greater; and (c) located in urban areas that offer different job opportunities than arise in rural areas. These types of selection are highly problematic because we cannot even sign the resulting bias. Moreover, they represent only some of the forms that selection (between brick-and-mortar and online) might take.

In some research, the controls are those who opt into the same treatment

33. Synthetic control methods would seem to be best, under the circumstances, if this empirical strategy were pursued. Matching methods would be more arbitrary given the large number of people who would match to each online enrollee.

34. See Miller (2009).

35. See Federal Communications Commission (2009). The report can be downloaded from the Wireline Competition Bureau Statistical Reports internet site at https://www.fcc.gov /general/iatd-data-statistical-reports. 
(online education) but at a different time. Thus, we might consider using people who will enroll in online education in the future as controls for people enroll in it now. The difficulty with doing this is that either we have to use controls who are in the same birth cohort as the treated people but who start online education at a later age or we have to use controls who are the same age as the treated people when they start online education but who start it in a different year. In the former case, the controls are problematic because the effect of education on earnings is likely to change with the age at which a person engages in education. In the latter case, the controls are problematic because online education (availability, curriculum, degree programs) has been changing fairly rapidly over recent years. Again, it is difficult to sign the biases created by using later online students as controls for earlier online students.

A final control group one might consider are students who enroll in online education but then drop it so quickly that it is implausible that it could affect their earnings much via the learning channel. The advantage of these potential controls is that their enrollment may have been triggered by an event, and is plausibly similar to the events that trigger other students' longer enrollment episodes. However, this group would be problematic because their lack of persistence in online education could be driven by their low effort or inability to master material. But, their lack of persistence could equally be caused by an improvement in their earnings opportunities. Thus, if we were to use them as controls, we would be unable even to sign the bias they would introduce.

\subsubsection{Details on the Estimation Strategy Used}

In short I dismiss, after careful consideration, strategies that generate counterfactual earnings for online enrollees based on other people. Thus, I focus on the narrower problem of using their own preenrollment earnings to project what their later earnings would have been had they not enrolled. We should be especially cautious of overreliance on the data in the years that immediately precede enrollment. If those data represent an inherently transitory event from which the person's earnings would have quickly rebounded in any case, we ought not to use data from that period to project future earnings. At the other extreme, those data could represent the "new normal": what the person's earnings trajectory would have been had he not enrolled in online education.

Given that economics and the data give us little indication of how to choose between these two extremes, it seems best to proceed with a bounding strategy. I therefore estimate earnings projections for each person that do and do not rely on data from the period just before enrollment (up to three years' worth).

A remaining issue is what specification to use in this estimation procedure. The (natural) log of earnings tends to have a steadier annual increase than 
the level of earnings. Also, earnings tend to be log-normally distributed rather than normally distributed. One would like to allow both the level and growth of a person's log earnings to shift after an episode of online enrollment. Most persons' log earnings evolve with age in a manner that resembles a quadratic relationship: log earnings grow swiftly in a person's early career, but growth slows and earnings eventually plateau or even decline close to retirement. Little would be added by estimating a higher-order polynomial in age (see footnote 30 ).

Thus, I estimate the following regression of log earnings

$$
\ln \left(\text { earnings }_{i t}\right)=\alpha_{i}+\beta \operatorname{age}_{i t}+\gamma \operatorname{age}_{i t}^{2}+\varepsilon_{i t}
$$

where $\alpha_{i}$ is a person fixed effect that is estimated three different ways: (a) using all preenrollment ( $\left.t \leq t_{0}\right)$ observations, (b) using preenrollment observations except the two $\left(t \leq t_{0}-2\right)$ that immediately precede enrollment, and (c) using preenrollment observations except the three $\left(t \leq t_{0}-3\right)$ that immediately precede enrollment. Notice that none of these regressions makes use of earnings during enrollment since they are potentially directly affected by studying. Specifications (b) and (c) instantiate the theory that earnings immediately before enrollment reflect a transitory shock and that earnings would have bounced back to their previous path even in the absence of online education. Hereafter, I refer to specifications (a) through (c) as having "Ashenfelter discards" of zero, two, and three years. ${ }^{36}$

Once I have estimates from equation (2), I form ROIs using a discount rate of 3.5 percent because this corresponds approximately to annual wage inflation over the period I consider (Bureau of Labor Statistics 2017), but I obtain similar results using discount rates of 3 and 4 percent ${ }^{37}$ I compute ten-year ROIs (the ROI if we consider only the first ten years of earnings after the completion of the enrollment episode) because ten years is the standard length of a student loan. Thus, the ten-year ROI helps us understand whether a student could reasonably expect to pay off her loan if she borrowed to pay tuition. In addition, the ten-year ROI is appealing because it depends less on the discount rate and on the accuracy of the parameter estimates from equation (2). ${ }^{38}$ Since ROIs may differ by type of school (exclu-

36. Another issue is online enrollees who have no reported wage or salary earnings in a preyear. Such earnings are more likely to signal a period when the person was out of the labor force or when the person's reservation wage exceeded the wage he was offered. Because years with zero earnings are relatively rare, however, their exclusion has very little effect on the estimates. These alternative results are available from the author.

37. These results are available from the author.

38. In other words, if the parameter estimates are mistaken, the mistake may compound over the postenrollment years so that up-through-age-sixty-five estimates are more error prone than ten-year-out estimates. In particular, there are few data from people observed in their late fifties and sixties so predictions for those years are something of an extrapolation beyond the data. We would not want to focus on ROIs in which those predictions played much of a role. 
sively or mainly online), by undergraduate versus graduate education, and by the length of enrollment, I show ROIs for all these relevant subgroups.

For instance, suppose that the estimated coefficients from the all-onlinestudents regression that discards two preenrollment observations (but does not discard zero earnings) are designated by a circumflex $\left({ }^{\wedge}\right)$. Then the numerator for ROI in this case is the estimated gain in lifetime earnings

$$
\begin{array}{r}
{\left[\sum_{\tau=0}^{\lambda-1} y_{i, t_{0}+\tau}+\sum_{\tau=\lambda}^{\lambda+9} \frac{\exp \left[\left(\hat{\alpha}_{i}+\hat{\mu}\right)+(\hat{\beta}+\hat{\nu}) \operatorname{age}_{i, t_{0}+\tau}+(\hat{\gamma}+\hat{\rho}) \operatorname{age}_{i, t_{0}+\tau}^{2}\right]}{(1+\delta)^{\tau}}\right]} \\
-\left[\sum_{\tau=0}^{\lambda+9} \frac{\exp \left(\hat{\alpha}_{i}+\hat{\beta} \operatorname{age}_{i, t_{0}+\tau}+\hat{\gamma}^{\tau} \mathrm{age}_{i, t_{0}+\tau}^{2}\right)}{(1+\delta)^{\tau}}\right]
\end{array}
$$

where $\delta$ is the discount rate, $\lambda$ is the length of the enrollment episode, and all amounts are discounted back to year $t_{0}$. Equation (3) is the difference in a person's lifetime earnings depending on whether she does or does not enroll. The first term is her actual earnings while enrolled and projected earnings assuming that she does enroll. The second term is projected earnings assuming (counterfactually) that she does not enroll. ${ }^{39}$

The denominator contains the schooling costs associated with generating the earnings gain

$$
\sum_{\tau=0}^{\lambda-1} \frac{\text { Tuition Paid }}{(1+\delta)^{\tau}}
$$

or

$$
\sum_{\tau=0}^{\lambda-1} \frac{\text { Social Cost }_{i t}}{(1+\delta)^{\tau}}
$$

where expression (4) considers only the private costs paid by the student herself whereas expression (5) considers the full social cost of (equal to the core spending on) her education, regardless of who paid for it (the student herself or taxpayers).

If estimated ROI is greater than or equal to one, then the benefits generated by the enrollment episode apparently cover its direct costs. If estimated ROI is between zero and one, the episode generates benefits but they are insufficient to cover its direct costs. An ROI less than or equal to zero indicates that the episode generated no or negative benefits to earnings.

39. The parameters $\mu, \nu$, and $\rho$ are from a regression that allows the level of earnings and its relationship with age to shift at the end of the enrollment episode. In the theoretical literature on returns to human capital investment, ROI is sometimes written as (postepisode earnings if enroll minus postepisode earnings if do not enroll) divided by (schooling cost plus opportunity cost). However, this formula generates oddities when opportunity costs are negative, as they sometimes are in practice. Thus, for ROI, I use (postenrollment earnings if enroll minus postenrollment earnings if do not enroll) divided by (schooling cost). Note the difference between "postepisode" and "postenrollment." 


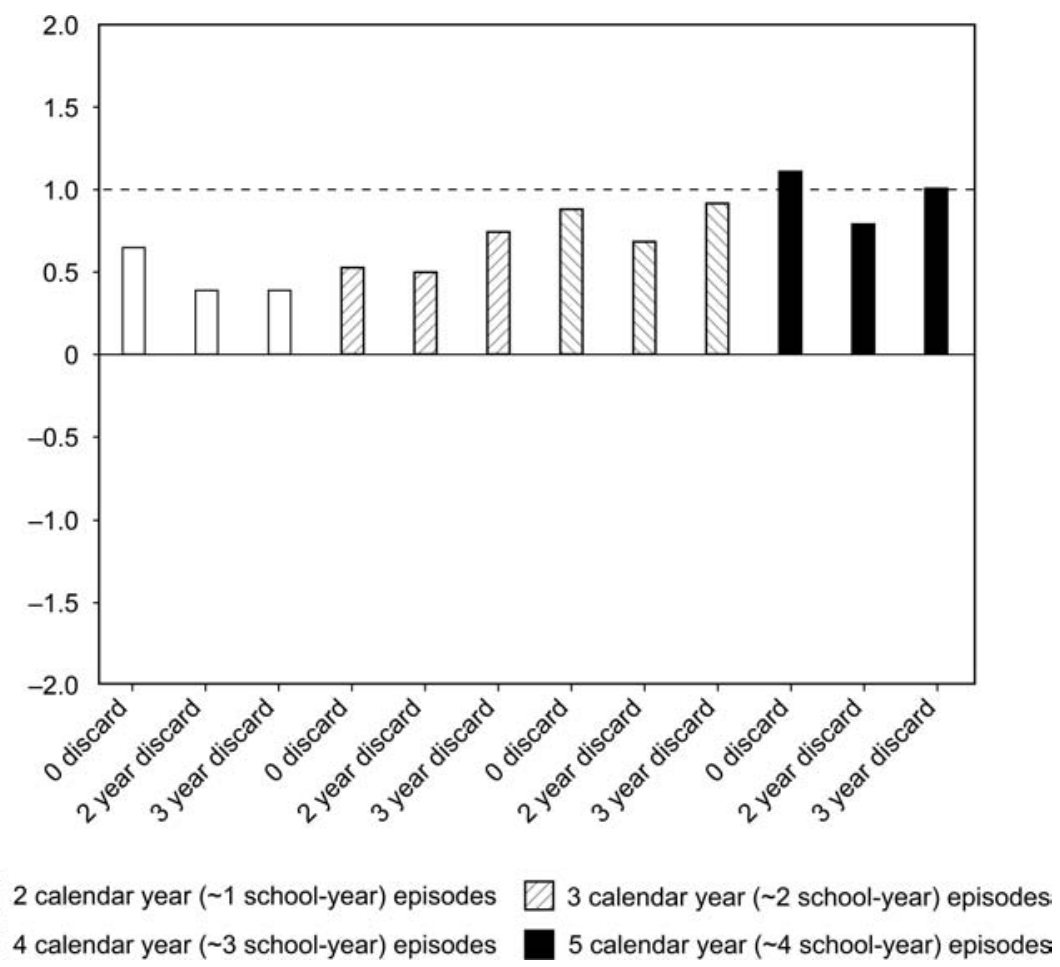

Fig. 11.16 ROIs of postsecondary episodes that were exclusively online

\subsection{Findings: Returns on Investment to Online Education}

The ROI estimates generated by the method just described are shown in figures 11.16-11.21, and appendix tables 11A.1-11A.3. The figures show only social ROIs and do not show ROIs for enrollment episodes that last only one calendar year (less than one school year) because they are somewhat unstable, owing to the small size of the denominator. ${ }^{40}$ The tables, however, show both social and private ROIs and include the estimates for one-calendar-year episodes. Both figures and tables show the median ROI for each subcategory of enrollment and Ashenfelter discard. (The mean ROIs are similar but less stable.)

Figure 11.16, for example, shows estimated social ROIs for postsecondary episodes of two to five calendar years (one to four school years) that were exclusively online. Episodes are included regardless of whether they were undergraduate or graduate. There is a horizontal line at ROI $=1$ as

40. In other words, very short enrollment episodes generate small direct costs, so modest changes in predicted earnings can generate large swings in ROIs. 


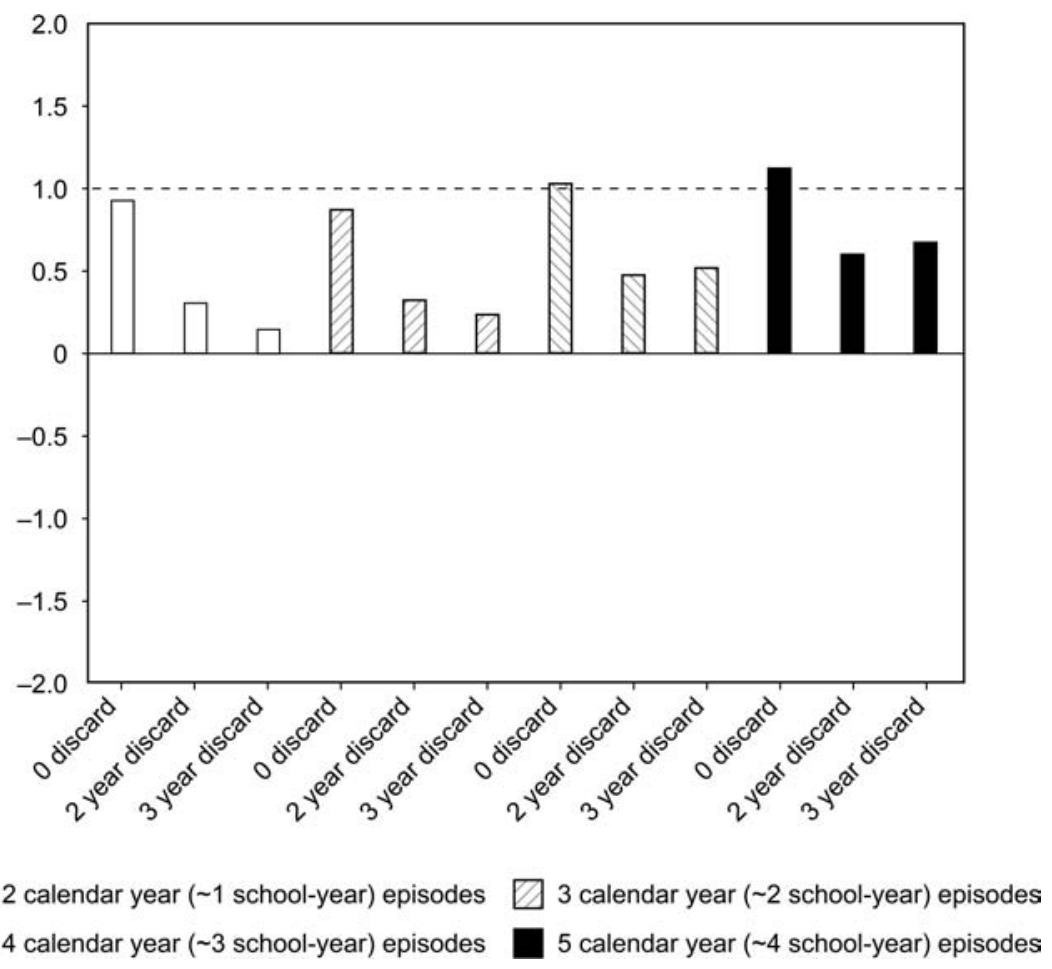

Fig. 11.17 ROIs of postsecondary episodes that were mainly online

a reminder that, below this line, the estimated benefits of the enrollment episode do not cover its costs. The finding that is immediately striking is that, regardless of the Ashenfelter discard, estimated ROIs are nearly all less than one. That is, regardless of whether we treat immediate preenrollment earnings as predictive or not, the ten-year returns to most online episodes do not cover the direct costs to society. The exceptions to this statement are the comparatively rare episodes that last five calendar years. Depending on the Ashenfelter discard, such episodes generate ROIs that range from 0.79 to 1.11. Keep in mind that episode length is not random: a student who elects to study for five calendar years may differ from one whose episode lasts only two or three years. Thus, we cannot conclude that the students whose episodes are shorter (and whose ROIs are uniformly less than one) would have better ROIs if only they had continued their studies through a fifth calendar year.

Figure 11.17 is analogous to figure 11.16 except that it shows ROIs for episodes that are mainly, rather than exclusively, online. Again, most of the estimated ROIs are less than one. The zero discard ROIs for four-year and five-year episodes are slightly greater than one: 1.03 and 1.12, respectively. 


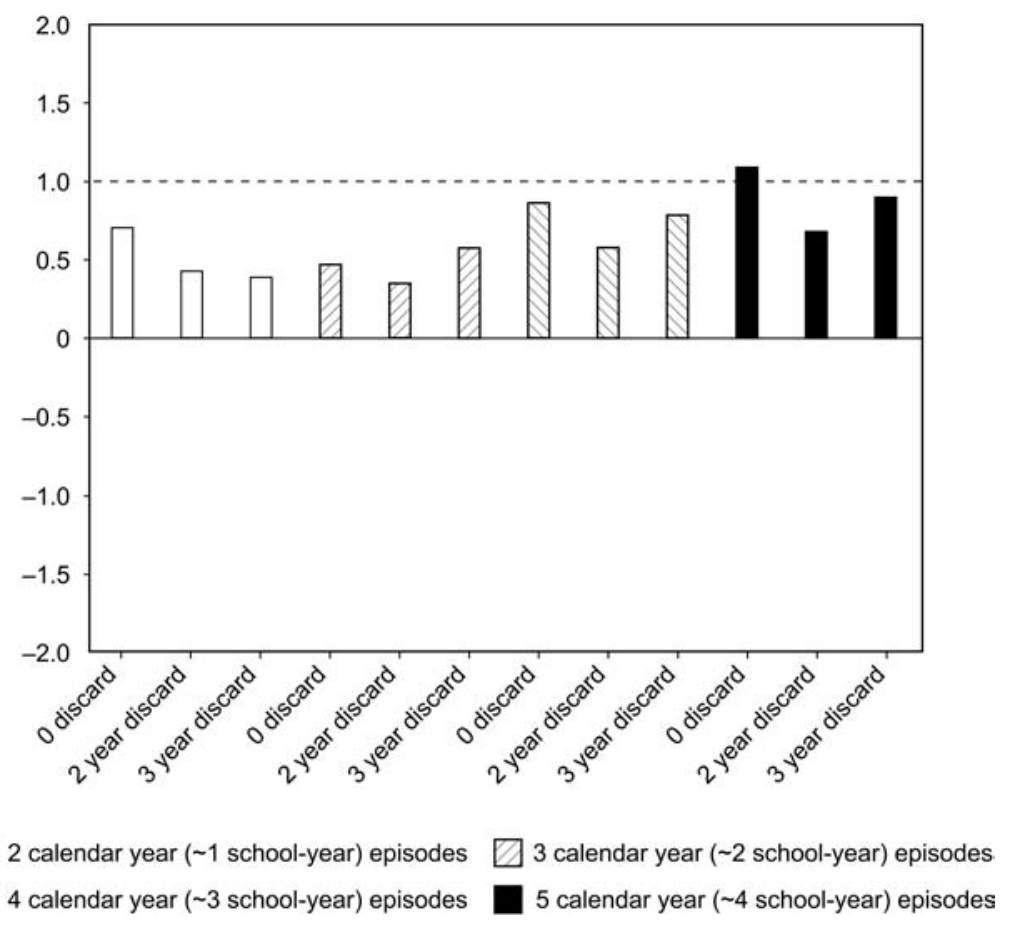

Fig. 11.18 ROIs of undergraduate postsecondary episodes that were exclusively online

However, even these modest results are not robust. The ROIs for these same episodes are substantially less than one with two-year or three-year Ashenfelter discards. Over all, the evidence suggests that the ten-year returns to mainly online episodes usually do not cover the direct costs to society.

Appendix table 11A.1 demonstrates that private ROIs are uniformly better than social ROIs. This is unsurprising, of course, because the private costs, which are in the denominator of the ROI equation, are uniformly smaller than social costs. (Recall the descriptive statistics in section 11.5.) The estimated private ROIs for two- and three-calendar-year episodes, which are fairly common, range from 0.61 to 1.17 for exclusively online education and range from 0.28 to 1.85 for mainly online education. However, two-thirds of the estimates for episodes of these lengths are less than one. Thus, such episodes may generate earnings that justify the tuition and fees that the person herself paid, but this conclusion depends on how one treats Ashenfelter's Dip. The estimated private ROIs for (comparatively rare) fourand five-calendar-year episodes are, with one exception, greater than one, suggesting that such episodes usually generate extra earnings that justify the tuition and fees paid by the student himself.

Figures 11.18 and 11.19 and appendix table 11A.2 show estimated ROIs 


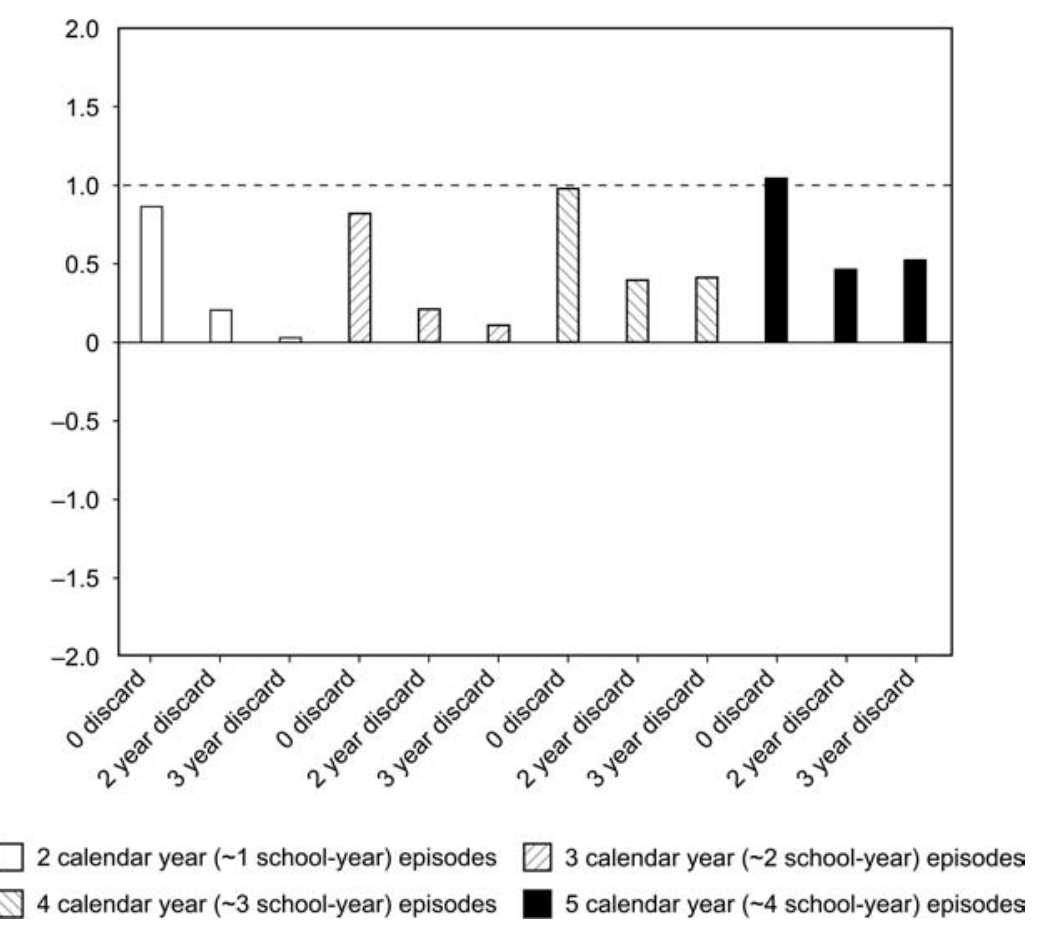

Fig. 11.19 ROIs of undergraduate postsecondary episodes that were mainly online

for undergraduate postsecondary episodes that are, respectively, exclusively and mainly online. The undergraduate ROIs are much like the overall ROIs shown in figures 11.16 and 11.17. Thus, the conclusions drawn in the paragraphs above also hold for undergraduate online education.

In contrast, figures 11.20 and 11.21 and appendix table 11A.3, which show estimated ROIs for graduate postsecondary episodes, suggest that the shorter (and much more common) episodes often generate negative ROIs. That is, when they enroll, people lose rather than gain earnings. The ROIs are especially poor for graduate education that is exclusively online. For twoand three-year episodes, they range from -0.91 to -1.73 . Even four- and five-calendar-year episodes of exclusively online graduate education have ROIs far less than one. Mainly online graduate education has somewhat better ROIs. They are far below one (and sometimes negative) for two- and three-calendar-year episodes, hover around one for four-year episodes, and are always well above one for the comparatively rare five-year episodes.

Summing up, the evidence suggests that the vast majority of online postsecondary enrollment, which tends to be in short episodes, generates earnings benefits that never cover social costs and probably do not even cover students' private costs. Four- and five-calendar-year enrollment episodes, 


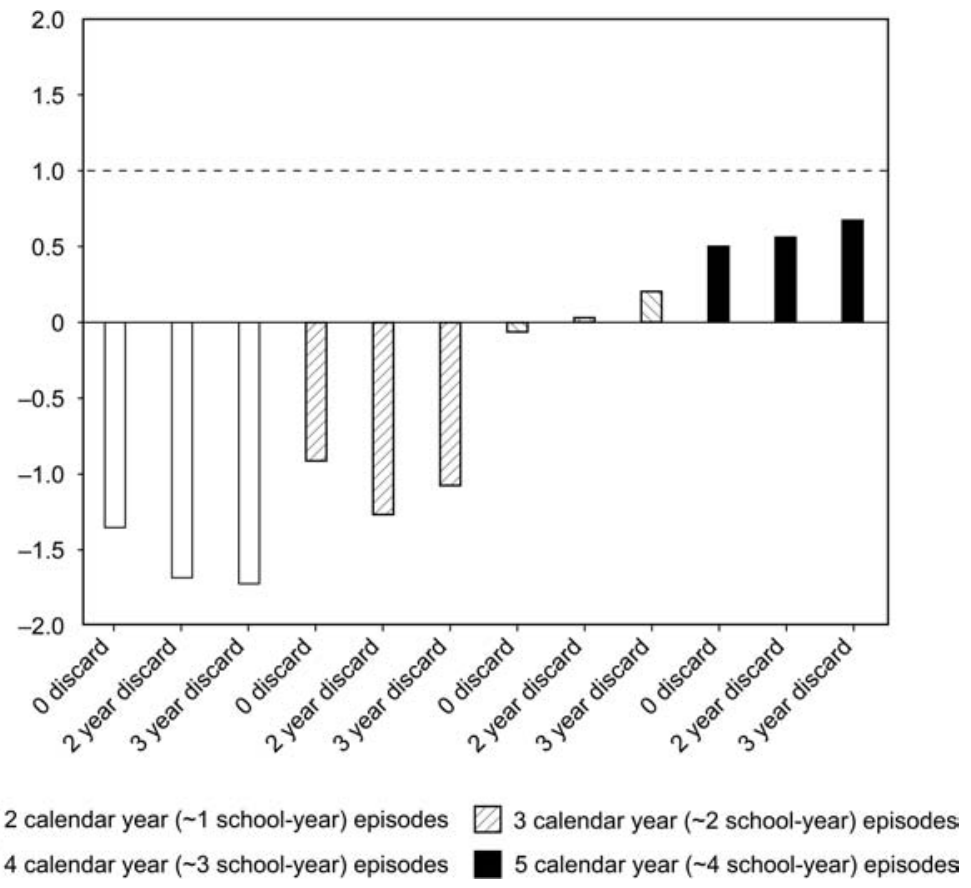

Fig. 11.20 ROIs of graduate postsecondary episodes that were exclusively online

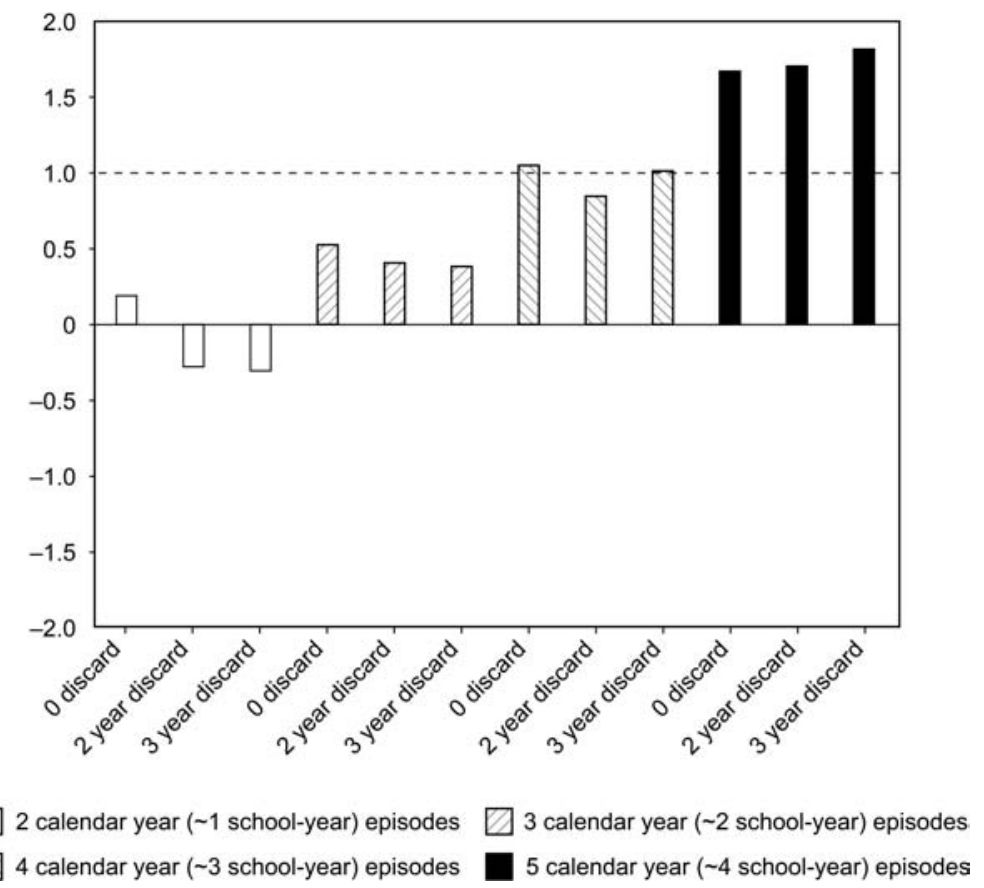

Fig. 11.21 ROIs of graduate postsecondary episodes that were mainly online 
which are comparatively rare, usually generate benefits that do not cover social costs but that do cover private costs. The exception is five-calendaryear graduate episodes at mainly online schools: their benefits appear to cover social costs as well as private costs. However, we should remind ourselves that the better results for students with five-year episodes do not imply that other students could obtain similar results if only they were to persist longer in online education. Such a conclusion would be wholly unwarranted, especially given how rare it is for students to self-select into long enrollment episodes.

\subsection{Do People Move into Higher Productivity Jobs after Online Enrollment?}

So far, the evidence suggests that returns to online postsecondary education are modest. This seems at odds with the logic of commentators, such as Beato and Christiansen, who argue that online education will disproportionately educate people in cutting-edge skills they need for technical, often computer-related, jobs in rapidly growing industries. Their arguments would suggest that online education allows students to move into industries that are high technology, have unusually high predicted employment growth, use abstract rather than routine or manual skills, and that are not offshorable (Autor and Dorn 2013)..$^{41}$ These are likely channels by which the online students' productivity might increase: improvements in their human capital that allow them to reallocate themselves to industries where productivity growth is higher.

In this section, I briefly examine evidence for these channels using figures much like those in section 11.6. Instead of showing earnings, however, the figures show (a) projected employment in a person's industry, ${ }^{42}$ (b) the percentage of occupations that are high technology in a person's industry, ${ }^{43}$ (c) the Autor-Dorn abstractness index for the skills required by a person's industry, (d) the analogous index for routine skills, (e) the analogous index for manual skills, and (f) the Autor-Dorn index of the offshorability of occupations in a person's industry. Figures 11.22-11.27 are for three-calendaryear enrollment episodes that are exclusively online. Figures 11.28-11.33 are for three-calendar-year enrollment episodes that are mainly online. I show only three-year episodes because they are common but nevertheless long enough for degree attainment. Also, the figures for episodes of other lengths

41. I rely throughout on Autor and Dorn's definitions of abstract, routine, and manual jobs. I also rely on their definition of offshorability.

42. I rely on the Employment Projects of the United States Bureau of Labor Statistics. Specifically, because its timing is appropriate for the students whose enrollment I examine, I use Figueroa and Woods (2007).

43. For data in which industries are high technology, I rely on Hecker (2005). However, the industries he defines as high technology in 2005 are nearly the same today. See Wolf and Terrell (2016). 


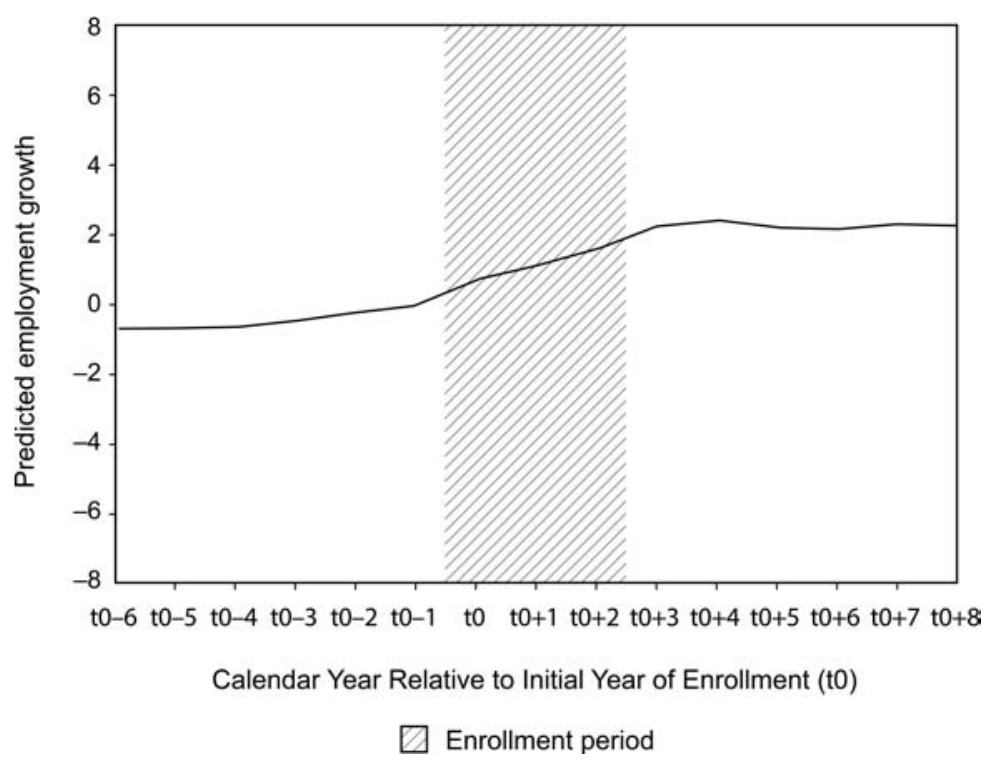

Fig. 11.22 Predicted employment growth before, during, and after a threecalendar-year episode of postsecondary enrollment that is exclusively online

Notes: Predicted employment growth in industry between 2012 and 2022. A standard deviation of this measure is 16 percentage points.

would not much affect the evidence ${ }^{44}$ All of the figures are designed so that the vertical axis represents one standard deviation in the measure of interest.

Consider figure 11.22, which shows the degree to which people move to a higher projected employment growth industry. There is certainly improvement on this measure: projected employment growth rises by 2.3 to 3 percentage points, which is 0.14 to 0.19 of a standard deviation. Interestingly, nearly all of the improvement occurs while the person is enrolled online.

Figure 11.23 shows, however, that the higher growth industries to which people are moving are not high-technology industries. In fact, the figure suggests that their employment in high technology is flat or slightly lower after their enrollment episode. However, the movement is very small. To see this, it is helpful to know how the Bureau of Labor Statistics flags determine the "high-tech-ness" of an industry. It flags certain occupations as indicators of high technology: engineers, life scientists, physical scientists, and computer systems managers. It then uses its industry-occupation matrix to assign hightech-ness to an industry based on the percentage of its occupations that are high technology. If this percentage rises by 1 percentage point, this can be interpreted as one in four or five students taking a job in one of the forty-six

44. The author can make available figures for episodes of other lengths and figures that separate undergraduates from graduate students. 


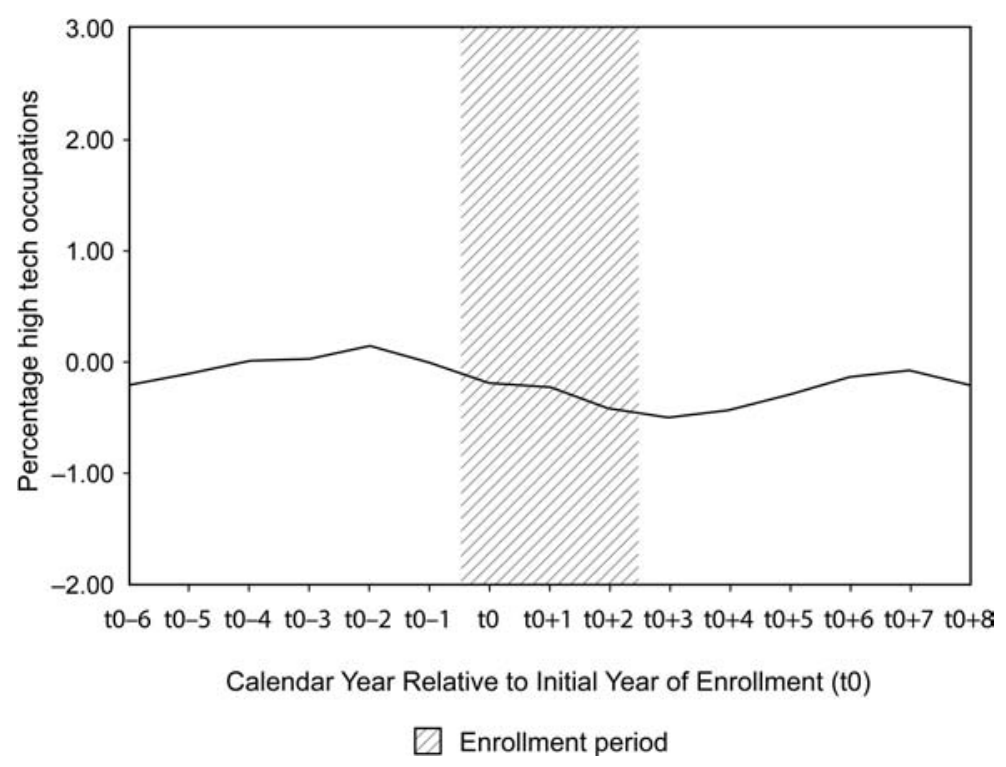

Fig. 11.23 Probability job is in high tech before, during, and after a three-calendaryear episode of postsecondary enrollment that is exclusively online

Notes: If percent of high-tech occupations rises by 1 percentage point, this can be interpreted as one in four or five students taking a job in one of the forty-six four-digit industries that are most high tech in the United States. This measure changes only when students change the industry of their jobs.

four-digit industries that are most high technology in the United States. A standard deviation in this measure is 5 percentage points.

Figures 11.24, 11.25, and 11.26 demonstrate that students are not moving into jobs that require greater abstract, routine, or manual skills after an enrollment episode that is exclusively online. A standard deviation in all these indices is 1 percentage point, and all of these indices fall by about 0.2 percentage points. The timing of the fall in abstractness hints that it is a causal effect of online enrollment. The declines in routineness and manualness appear simply to be trends that start before the episode and continue through it and after it. Together, this evidence suggests that students are moving (slightly) toward industries with occupations that could not be classified as abstract, routine, or manual. This could be a good sign for productivity if such occupations are unclassified because they are novel. It could equally be a bad sign. In any case, there is no evidence for students moving into the more abstract jobs associated with higher productivity growth.

Figure 11.27 shows that students are also not moving away from offshorable jobs. Before, during, and after their online enrollment, they are 


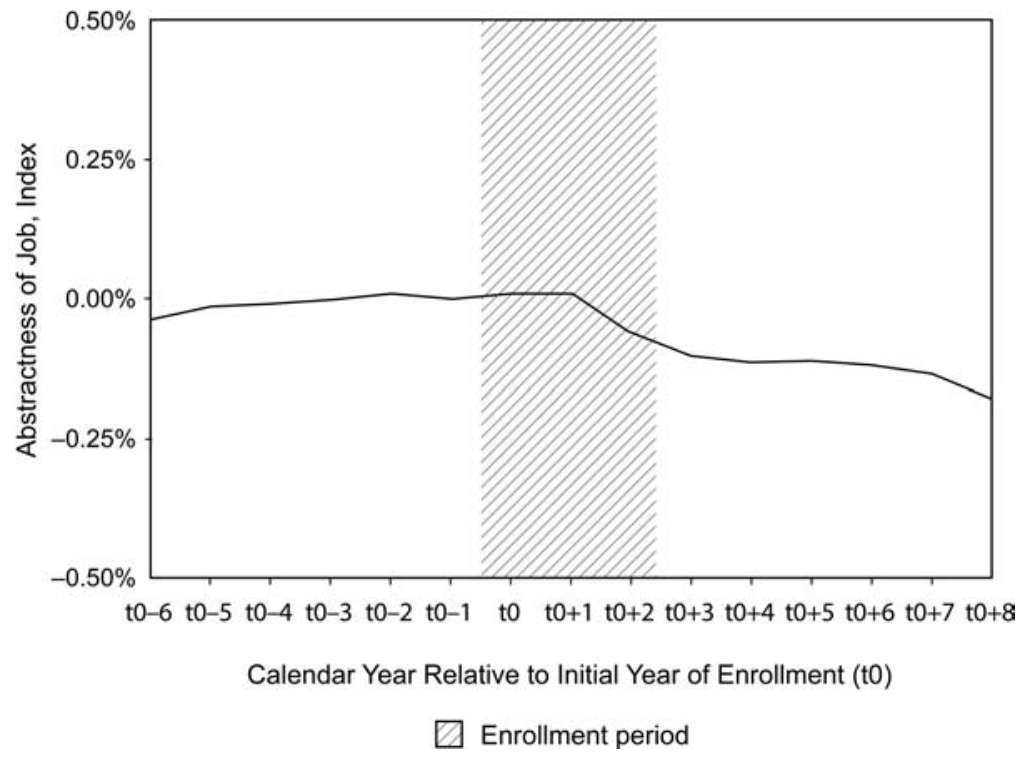

Fig. 11.24 "Abstractness" of job before, during, and after a three-calendar-year episode of postsecondary enrollment that is exclusively online

Notes: Abstractness is measured by the Autor-Dorn index of the skills required in the industry. A standard deviation in this index is about 1 percentage point. This measure changes only when students change the industry of their jobs.

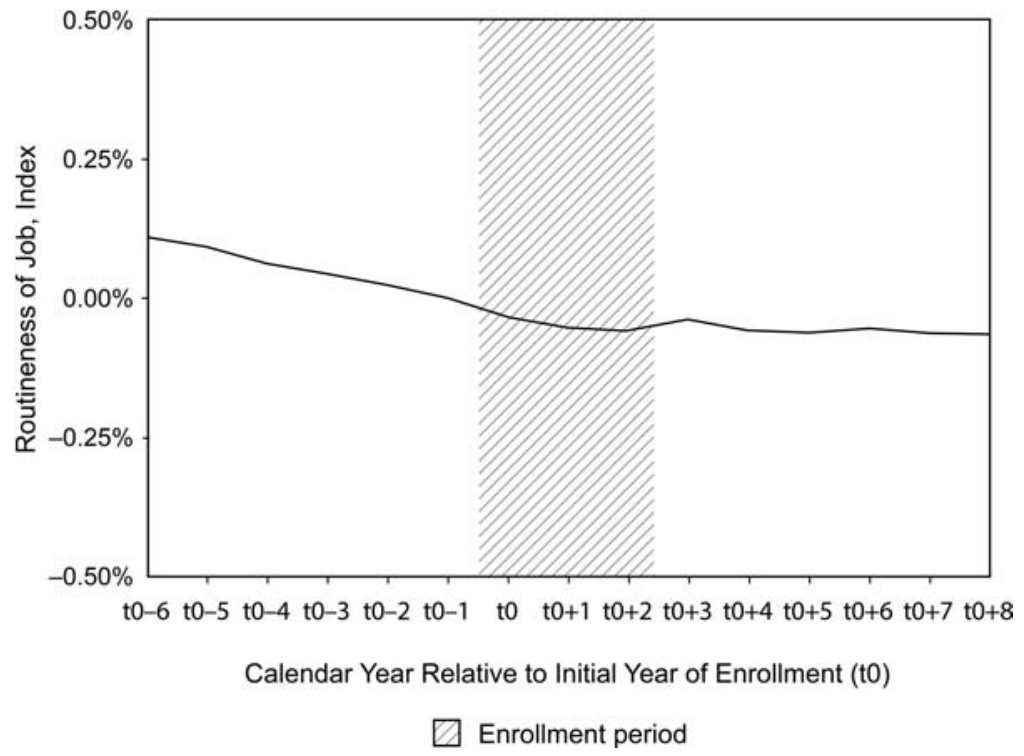

Fig. 11.25 "Routineness" of job before, during, and after a three-calendar-year episode of postsecondary enrollment that is exclusively online

Notes: Routineness is measured by the Autor-Dorn index of the skills required in the industry. A standard deviation in this index is about 1 percentage point. This measure changes only when students change the industry of their jobs. 


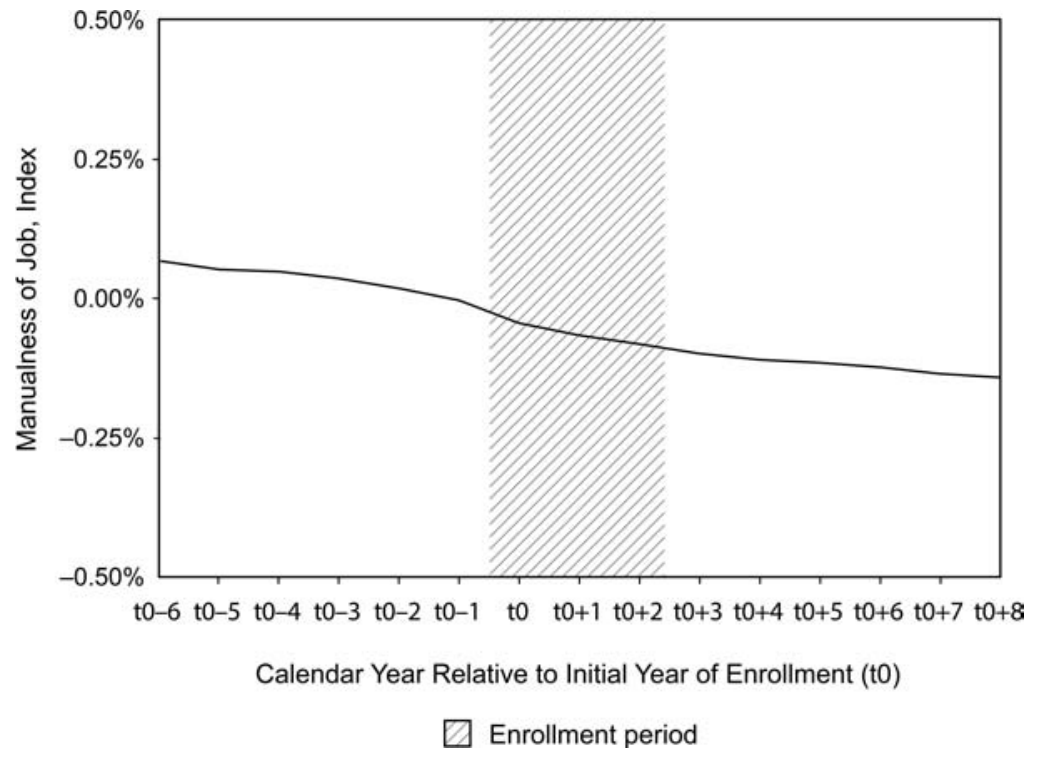

Fig. 11.26 "Manualness" of job before, during, and after a three-calendar-year episode of postsecondary enrollment that is exclusively online

Notes: Manualness is measured using the Autor-Dorn index of the skills required in the industry. A standard deviation in this index is about 1 percentage point. This measure changes only if students change the industry of their jobs.

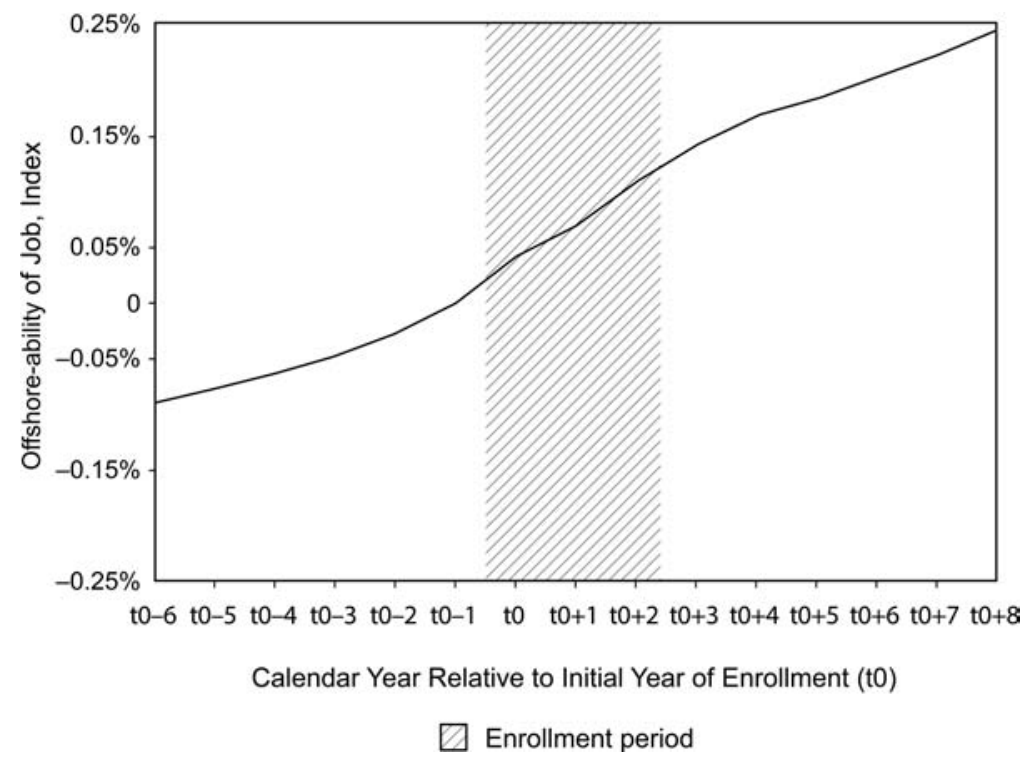

Fig. 11.27 "Offshorability" of job before, during, and after a three-calendar-year episode of postsecondary enrollment that is exclusively online

Notes: Offshorability is measured using the Autor-Dorn index. A standard deviation in this index is about 0.5 percentage points. This measure changes only when students change the industry of their jobs. 


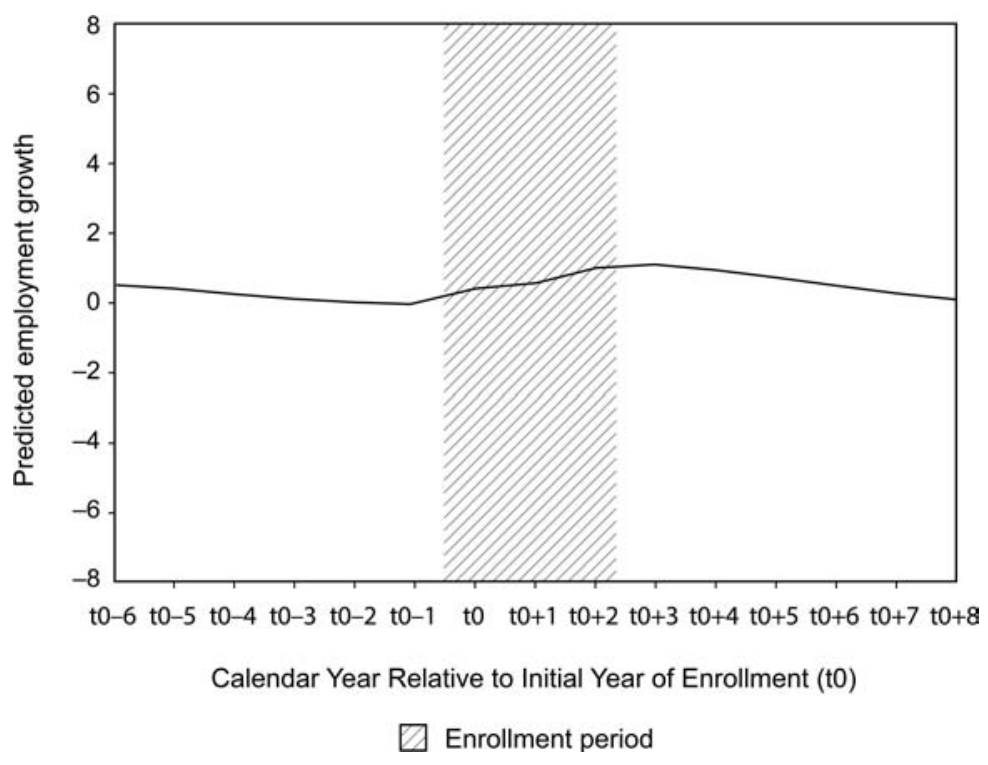

Fig. 11.28 Prospective growth in students' industry before, during, and after a three-calendar-year episode of postsecondary enrollment that is mainly online

Notes: Predicted employment growth in students' industry between 2012 and 2022. A standard deviation in this measure is 16 percentage points. This measure changes only when students change the industry of their jobs.

moving into industries that are more offshorable. The trend appears to be unaffected by enrollment.

Mainly online education generates somewhat different patterns. Figure 11.28 shows little indication that mainly online students move into industries with higher projected earnings growth after enrolling. Figure 11.29 suggests that enrollment also does not affect their tendency to join a hightechnology industry. They are moving into high-technology industries before, during, and after their episode, but the trend is unaffected. The abstractness of the students' jobs rises quickly while they are enrolled: 0.17 standard deviations ( 0.17 percentage points) in just three years. (See figure 11.30.) However, after the episode, abstractness rises more slowly than it was rising before the episode enrollment. People end up at about the same level of abstractness as their preenrollment trend would have predicted. Finally, figures $11.31,11.32$, and 11.33 show little or no evidence that mainly online enrollment affects the routineness, manualness, or offshorability of a person's job.

Overall, the evidence is slight for the hypothesis that online education shifts people into higher productivity industries. It seems likely that commentators who emphasize that online education generates cutting-edge, high-technology, abstract skills are focusing on programs that and/or students who are highly nonrepresentative. The nonrepresentativeness of their 


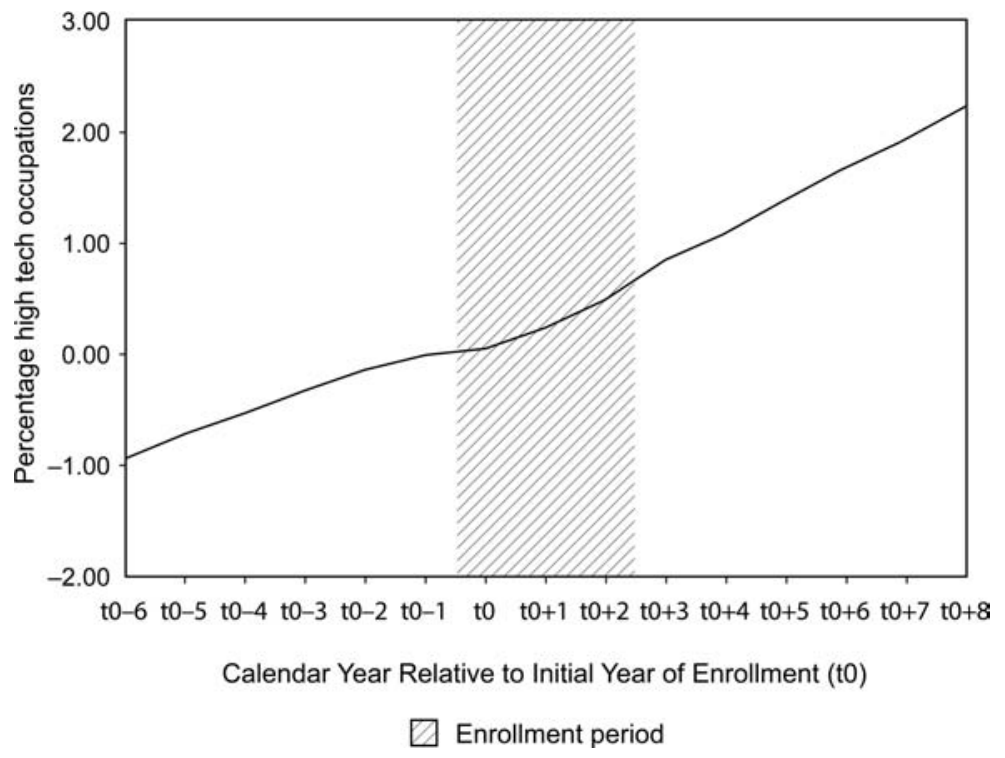

Fig. 11.29 Probability job is in high tech before, during, and after a three-calendaryear episode of postsecondary enrollment that is mainly online

Notes: If percent of high-tech occupations rises by 1 percentage point, this can be interpreted as one in five students taking a job in one of the forty-six four-digit industries that are most high tech in the United States. This measure changes only when students change the industry of their jobs.

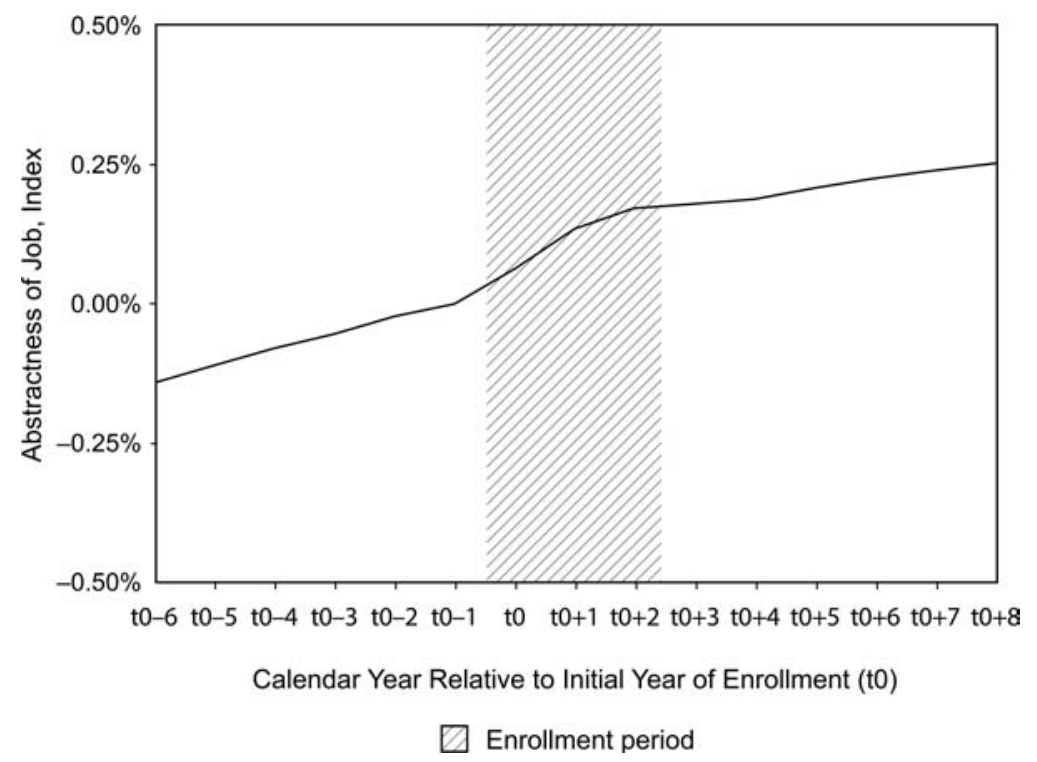

Fig. 11.30 "Abstractness" of job before, during, and after a three-calendar-year episode of postsecondary enrollment that is mainly online

Notes: Abstractness is measured by the Autor-Dorn index of the skills required in the industry. A standard deviation in this index is about 1 percentage point. This measure changes only when students change the industry of their jobs. 


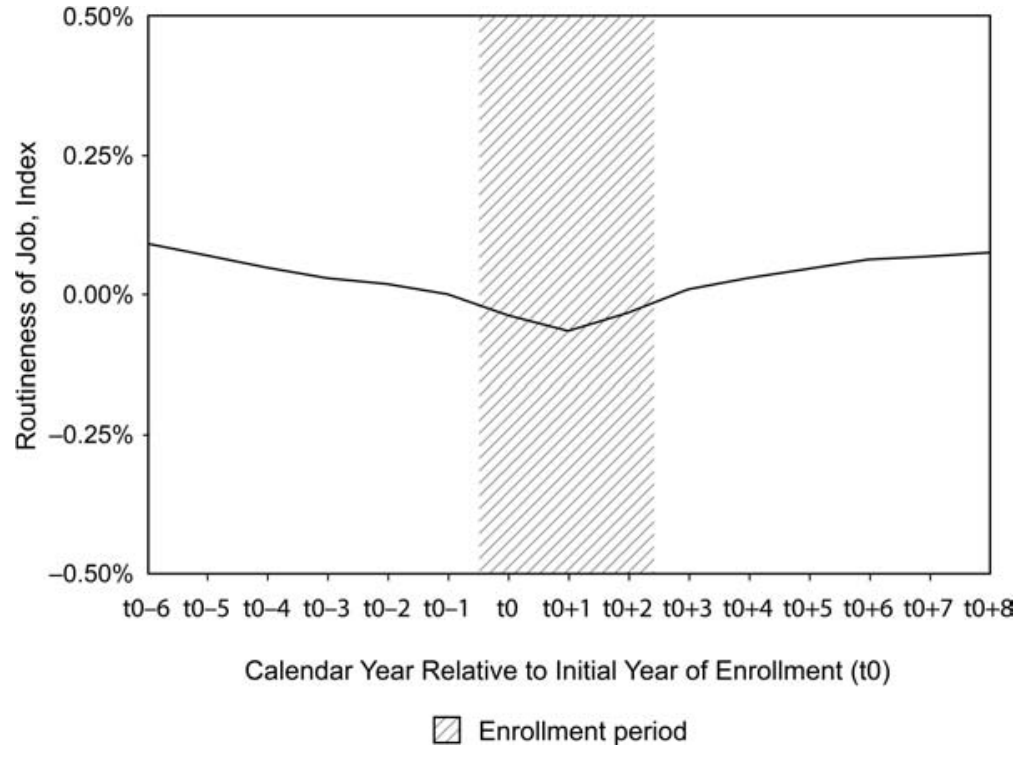

Fig. 11.31 "Routineness" of job before, during, and after a three-calendar-year episode of postsecondary enrollment that is mainly online

Notes: Routineness is measured by the Autor-Dorn index of the skills required in the industry. A standard deviation in this index is about 1 percentage point. This measure changes only when students change the industry of their jobs.

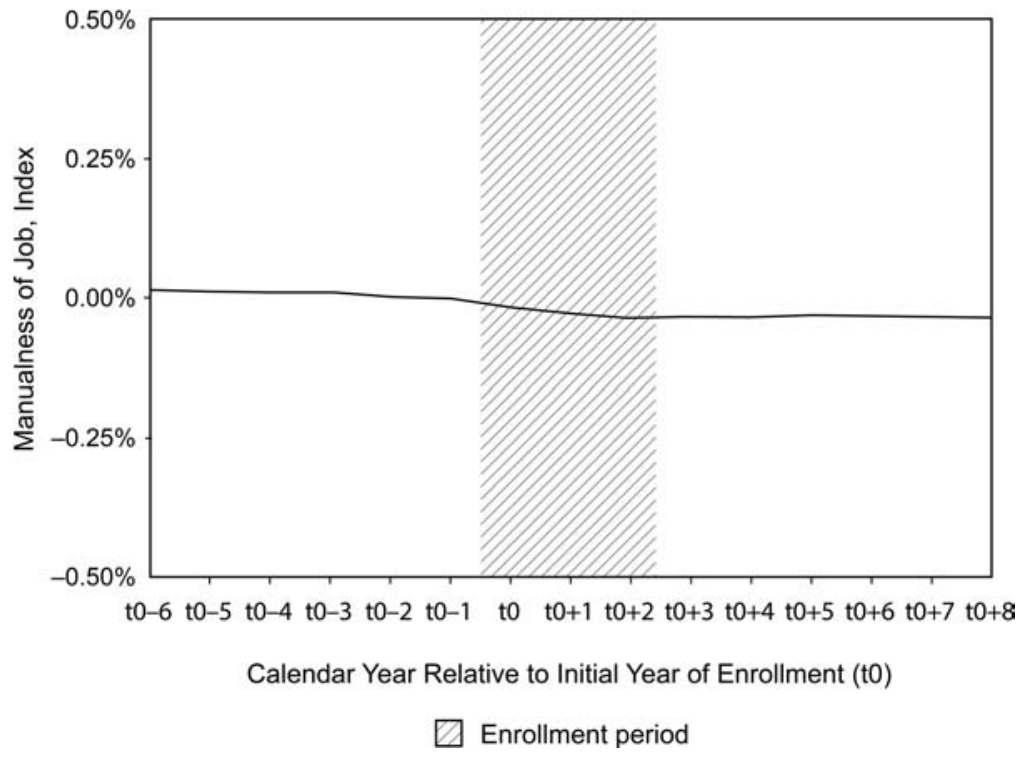

Fig. 11.32 "Manualness" of job before, during, and after a three-calendar-year episode of postsecondary enrollment that is mainly online

Notes: Manualness is measured by the Autor-Dorn index of the skills required in the industry. A standard deviation in this index is about 1 percentage point. This measure changes only when students change the industry of their jobs. 


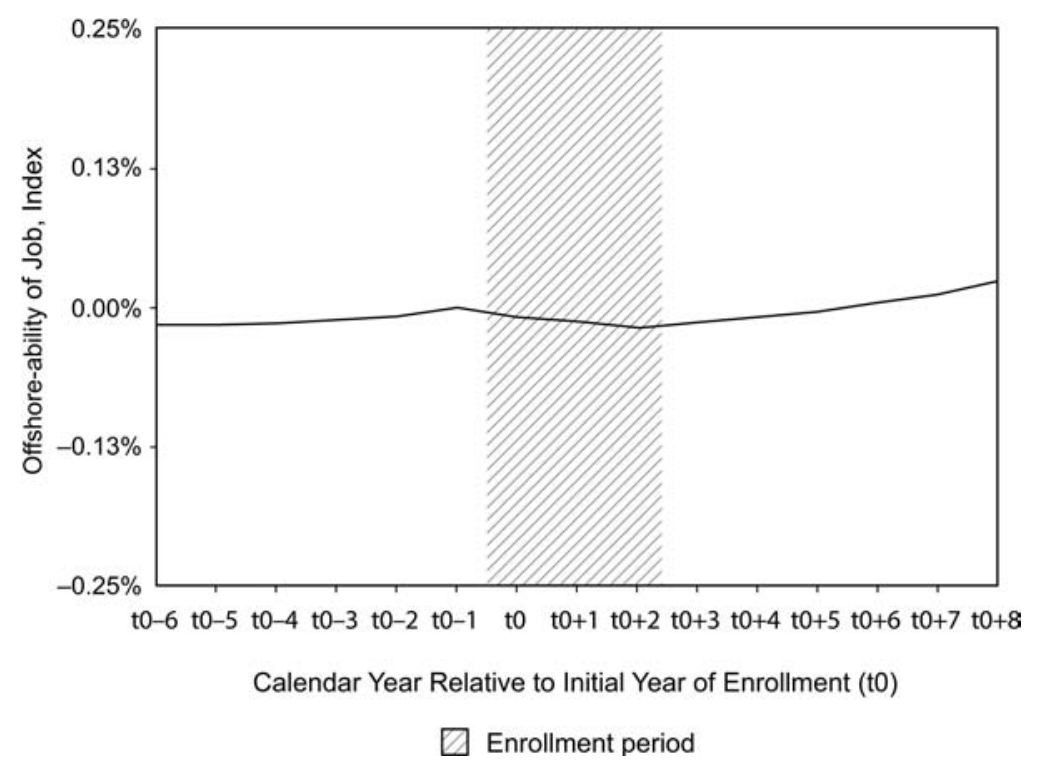

Fig. 11.33 "Offshorability" of job before, during, and after a three-calendar-year episode of postsecondary enrollment that is mainly online

Notes: Offshorability is measured by the Autor-Dorn index. A standard deviation in this index is about 0.5 percentage points. This measure changes only when students change the industry of their jobs.

descriptions is confirmed by the studies cited in footnote 6 , none of which suggests that advanced or leading-edge courses are prevalent on online education. They suggest that introductory courses dominate.

\subsection{Online Education from the Federal Taxpayer's Point of View}

As noted in section 11.5, federal taxpayers foot a substantial share of the cost of online postsecondary education. Are they at all likely to recoup their investment? The estimated ROIs suggest not.

For instance, the average social cost of a year of exclusively online postsecondary school is $\$ 8,325$, of which $\$ 3,620$ (43.5 percent) is funded up front by federal taxpayers through grants and tax expenditures. Given that social ROIs are below one for exclusively online education and that students never face federal tax rates greater than 43.5 percent, it is not possible that they will repay current federal taxpayers through higher future federal income tax payments. Moreover, because private ROIs are also often well below one for exclusively online education, many students will be unable to repay their federal loans out of higher earnings. Thus, we should not be surprised they are overrepresented among loan defaulters and people who enter income-based repayment schemes through which they are likely to end up repaying only a fraction of what they owe. If students at exclusively online schools repay only 
50 percent of their loans, federal taxpayers will have funded 69 percent of the cost of their education with little recoupment through higher future taxes.

Similar calculations can be made for mainly online students. The average social cost of a year of such education is $\$ 10,380$, of which $\$ 3,699$ (35.6 percent) is funded up front by federal taxpayers through grants and tax expenditures. Because social ROIs for mainly online schooling are below one and former students are extremely unlikely to pay federal income tax rates above 35.6 percent, current taxpayers cannot recoup their investment in mainly online education through students' higher future tax payments. Moreover, the low private ROIs for most mainly online education suggest that students will fail to repay their loans, which average $\$ 5,075$ per year, in full. If they repay only 50 percent of their loans, federal taxpayers will have funded 60 percent of the total cost of mainly online education.

\subsection{Conclusions}

This study attempts a fairly comprehensive examination of online postsecondary education and its effects on students' later earnings and job outcomes. It also calculates ROIs. On the whole, I find little support for optimistic prognostications about online education. It is not substantially less expensive for society than comparably selective in-person education, although of course its costs may fall in the future as online schools gain experience. Students themselves pay more for online education than in-person education even though the resources devoted to their instruction are lower. Online enrollment episodes do usually raise students' earnings, but almost never by an amount that covers the social cost of their education. This failure to cover social costs is important for taxpayers, especially for federal taxpayers who are the main funders of online education apart from the students themselves. The failure implies that federal income tax revenues associated with future increased earnings could not come close to repaying current taxpayers.

Most online students' earnings do not rise by an amount that covers even their private costs - the tuition and fees that they themselves, as opposed to governments, pay. This suggests that former online students will struggle to repay their federal loans. Only online students who persist through unusually long enrollment episodes (four or five calendar years) experience earnings increases that usually cover their private costs. We cannot infer from this evidence, however, that students whose online enrollment episodes are short would experience similar benefits if they persisted for more years. Indeed, they may be dropping out precisely because they foresee that their benefits will not be sufficient to justify the costs.

There is only slight evidence that online enrollment moves people toward jobs associated with higher productivity growth. Online enrollment appears to have little or no effect on a person's probability of holding a hightechnology job or a job that requires abstract skills. 
Overall, the main contribution of this study may be to ground the discussion of online postsecondary education in evidence. Much of the discussion to this point may suffer from undue optimism or pessimism because such evidence has been lacking.

\section{Appendix}

Table 11A.1 Median ROI values for online postsecondary education episodes of
various lengths

\begin{tabular}{lcc}
\hline & Exclusively online & Mainly online \\
\hline Two-calendar-year (one-school-year) episodes & & \\
Social ROI with no Ashenfelter discard & 0.64 & 0.93 \\
Social ROI with two-year Ashenfelter discard & 0.39 & 0.30 \\
Social ROI with three-year Ashenfelter discard & 0.39 & 0.14 \\
Private ROI with no Ashenfelter discard & 1.01 & 1.85 \\
Private ROI with two-year Ashenfelter discard & 0.62 & 0.59 \\
Private ROI with three-year Ashenfelter discard & 0.61 & 0.28 \\
Three-calendar-year (two-school-year) episodes & & \\
Social ROI with no Ashenfelter discard & 0.53 & 0.88 \\
Social ROI with two-year Ashenfelter discard & 0.50 & 0.33 \\
Social ROI with three-year Ashenfelter discard & 0.75 & 0.24 \\
Private ROI with no Ashenfelter discard & 0.84 & 1.75 \\
Private ROI with two-year Ashenfelter discard & 0.79 & 0.65 \\
Private ROI with three-year Ashenfelter discard & 1.17 & 0.47 \\
Four-calendar-year (three-school-year) episodes & & \\
Social ROI with no Ashenfelter discard & 0.88 & 1.03 \\
Social ROI with two-year Ashenfelter discard & 0.68 & 0.47 \\
Social ROI with three-year Ashenfelter discard & 0.91 & 0.51 \\
Private ROI with no Ashenfelter discard & 1.39 & 2.04 \\
Private ROI with two-year Ashenfelter discard & 1.06 & 0.93 \\
Private ROI with three-year Ashenfelter discard & 1.43 & 1.01 \\
Five-calendar-year (four-school-year) episodes & & \\
Social ROI with no Ashenfelter discard & 1.11 & 1.12 \\
Social ROI with two-year Ashenfelter discard & 0.79 & 0.60 \\
Social ROI with three-year Ashenfelter discard & 1.01 & 0.66 \\
Private ROI with no Ashenfelter discard & 1.74 & 2.24 \\
Private ROI with two-year Ashenfelter discard & 1.24 & 1.20 \\
Private ROI with three-year Ashenfelter discard & 1.58 & 1.30 \\
One-calendar-year (part-school-year) episodes & & \\
Social ROI with no Ashenfelter discard & 0.96 & 2.14 \\
Social ROI with two-year Ashenfelter discard & 1.00 & 6.08 \\
Social ROI with three-year Ashenfelter discard & 1.18 & 4.13 \\
Private ROI with no Ashenfelter discard & 1.50 & 1.58 \\
Private ROI with two-year Ashenfelter discard & 1.85 & \\
Private ROI with three-year Ashenfelter discard & & \\
\hline & & \\
\hline
\end{tabular}

${ }^{\text {aT }}$ These estimates are not stable. See text. 
Table 11A.2 Median ROI values for online undergraduate postsecondary education episodes of various lengths

\begin{tabular}{lcc}
\hline & Exclusively online & Mainly online \\
\hline Two-calendar-year (one-school-year) episodes & & \\
Social ROI with no Ashenfelter discard & 0.71 & 0.87 \\
Social ROI with two-year Ashenfelter discard & 0.43 & 0.21 \\
Social ROI with three-year Ashenfelter discard & 0.39 & 0.02 \\
Private ROI with no Ashenfelter discard & 1.11 & 1.72 \\
Private ROI with two-year Ashenfelter discard & 0.68 & 0.42 \\
Private ROI with three-year Ashenfelter discard & 0.61 & 0.04 \\
Three-calendar-year (two-school-year) episodes & & \\
Social ROI with 0 no Ashenfelter discard & 0.47 & 0.82 \\
Social ROI with two-year Ashenfelter discard & 0.35 & 0.21 \\
Social ROI with three-year Ashenfelter discard & 0.58 & 0.11 \\
Private ROI with no Ashenfelter discard & 0.74 & 1.63 \\
Private ROI with two-year Ashenfelter discard & 0.55 & 0.42 \\
Private ROI with three-year Ashenfelter discard & 0.91 & 0.21 \\
Four-calendar-year (three-school-year) episodes & & \\
Social ROI with no Ashenfelter discard & 0.86 & 0.98 \\
Social ROI with two-year Ashenfelter discard & 0.58 & 0.39 \\
Social ROI with three-year Ashenfelter discard & 0.79 & 0.41 \\
Private ROI with no Ashenfelter discard & 1.35 & 1.95 \\
Private ROI with two-year Ashenfelter discard & 0.91 & 0.77 \\
Private ROI with three-year Ashenfelter discard & 1.24 & 0.82 \\
Five-calendar-year (four-school-year) episodes & & \\
Social ROI with no Ashenfelter discard & 1.09 & 1.04 \\
Social ROI with two-year Ashenfelter discard & 0.68 & 0.46 \\
Social ROI with three-year Ashenfelter discard & 0.90 & 0.52 \\
Private ROI with no Ashenfelter discard & 1.71 & 2.07 \\
Private ROI with two-year Ashenfelter discard & 1.07 & 0.92 \\
Private ROI with three-year Ashenfelter discard & 1.41 & 1.02 \\
One-calendar-year (part-school-year) episodes & \\
Social ROI with no Ashenfelter discard & & \\
Social ROI with two-year Ashenfelter discard & 1.07 & 3.85 \\
Social ROI with three-year Ashenfelter discard & 1.07 & 3.73 \\
Private ROI with no Ashenfelter discard & 1.67 & \\
Private ROI with two-year Ashenfelter discard & 1.68 & 2.05 \\
Private ROI with three-year Ashenfelter discard & & \\
\hline & & \\
\hline
\end{tabular}

${ }^{a}$ These estimates are not stable. See text. 


\begin{tabular}{lcr}
\hline & Exclusively online & Mainly online \\
\hline Two-calendar-year (two-school-year) episodes & & \\
Social ROI with no Ashenfelter discard & -1.36 & 0.19 \\
Social ROI with two-year Ashenfelter discard & -1.69 & -0.28 \\
Social ROI with three-year Ashenfelter discard & -1.73 & -0.31 \\
Private ROI with no Ashenfelter discard & -2.13 & 0.37 \\
Private ROI with two-year Ashenfelter discard & -2.65 & -0.56 \\
Private ROI with three-year Ashenfelter discard & -2.72 & -0.61 \\
Three-calendar-year (two-school-year) episodes & & \\
Social ROI with no Ashenfelter discard & -0.91 & 0.51 \\
Social ROI with two-year Ashenfelter discard & -1.26 & 0.40 \\
Social ROI with three-year Ashenfelter discard & -1.08 & 0.38 \\
Private ROI with no Ashenfelter discard & -1.43 & 1.02 \\
Private ROI with two-year Ashenfelter discard & -1.98 & 0.79 \\
Private ROI with three-year Ashenfelter discard & -1.69 & 0.76 \\
Four-calendar-year (three-school-year) episodes & & \\
Social ROI with no Ashenfelter discard & -0.06 & 1.05 \\
Social ROI with two-year Ashenfelter discard & 0.03 & 0.85 \\
Social ROI with three-year Ashenfelter discard & 0.20 & 1.01 \\
Private ROI with no Ashenfelter discard & -0.10 & 2.09 \\
Private ROI with two-year Ashenfelter discard & 0.05 & 1.69 \\
Private ROI with three-year Ashenfelter discard & 0.31 & 2.02 \\
Five-calendar-year (four-school-year) episodes & & \\
Social ROI with no Ashenfelter discard & 0.50 & 1.67 \\
Social ROI with two-year Ashenfelter discard & 0.56 & 1.71 \\
Social ROI with three-year Ashenfelter discard & 0.67 & 1.82 \\
Private ROI with no Ashenfelter discard & 0.79 & 3.33 \\
Private ROI with two-year Ashenfelter discard & 0.88 & 3.40 \\
Private ROI with three-year Ashenfelter discard & 1.05 & 3.62 \\
One-calendar-year (part-school-year) episodes & & \\
Social ROI with no Ashenfelter discard & -1.91 & 1.02 \\
Social ROI with two-year Ashenfelter discard & -0.84 & 2.03 \\
Social ROI with three-year Ashenfelter discard & -1.52 & -3.00 \\
Private ROI with no Ashenfelter discard & -1.31 & -2.39 \\
Private ROI with two-year Ashenfelter discard & & \\
Private ROI with three-year Ashenfelter discard & & \\
\hline & & \\
\hline
\end{tabular}

${ }^{\mathrm{a}}$ These estimates are not stable. See text. 


\section{References}

Ashenfelter, Orley, and David Card. 1985. "Using the Longitudinal Structure of Earnings to Estimate the Effect of Training Programs." Review of Economics and Statistics 67 (4): 648-60.

Autor, David H., and David Dorn. 2013. "The Growth of Low-Skill Service Jobs and the Polarization of the US Labor Market." American Economic Review 103 (5): 1553-97.

Beato, Greg. 2014. "Online Higher Education Retools.” Reason, Feb. 24. Accessed Jan. 2017. http://reason.com/archives/2014/02/24/online-higher-education-retool /print.

Bettinger, Eric, Lindsay Fox, Susanna Loeb, and Eric Taylor. 2014. "Changing Distributions: How Online College Classes Alter Student and Professor Performance." Unpublished manuscript, Stanford University.

Bowen, William G., Matthew M. Chingos, Kelly A. Lack, and Thomas I. Nygren. 2014. "Interactive Learning Online at Public Universities: Evidence from a SixCampus Randomized Trial." Journal of Policy Analysis and Management 33 (1): 94-111.

Bureau of Labor Statistics. 2017. "Employment Cost Index, Historical Listing Volume III.” National Compensation Survey, Jan. 2017 edition. https://www.bls.gov /web/eci/echistrynaics.pdf.

Christensen, Clayton M., and Henry J. Eyring. 2011. The Innovative University: Changing the DNA of Higher Education from the Inside Out. Hoboken, NJ: John Wiley \& Sons.

Christensen, Clayton M., and Michael B. Horn. 2013. "Innovation Imperative: Change Everything: Online Education as an Agent of Transformation." New York Times, Nov. 1. Accessed Jan. 2017. http://www.nytimes.com/2013/11/03/education /edlife/online-education-as-an-agent-of-transformation.html.

Cowen, Tyler, and Alex Tabarrok. 2014. "The Industrial Organization of Online Education." American Economic Review 104 (5): 519-22.

Deming, David J., Claudia Goldin, and Lawrence F. Katz. 2012. "The For-Profit Postsecondary School Sector: Nimble Critters or Agile Predators?" Journal of Economic Perspectives 26 (1): 139-63.

Deming, David J., Claudia Goldin, Lawrence F. Katz, and Noam Yuchtman. 2015. "Can Online Learning Bend the Higher Education Cost Curve?" American Economic Review 105 (5): 496-501.

Deming, David J., Michael Lovenheim, and Richard Patterson. Forthcoming. "The Competitive Effects of Online Education.” In Productivity in Higher Education, edited by Caroline M. Hoxby and Kevin Stange. Chicago: University of Chicago Press.

Federal Communications Commission. 2009. "High-Speed Services for Internet Access: Status as of June 30, 2008." FCC Report. https://www.fcc.gov/wcb/stats.

Figlio, David, Mark Rush, and Lu Yin. 2013. "Is It Live or Is It Internet? Experimental Estimates of the Effects of Online Instruction on Student Learning." Journal of Labor Economics 31 (4): 763-84.

Figueroa, Eric B., and Rose A. Woods. 2007. "Industry Output and Employment Projections to 2016." Monthly Labor Review November: 53-85.

Hart, Cassandra, Elizabeth Friedmann, and Michael Hill. 2014. "Online CourseTaking and Student Outcomes in California Community Colleges." Conference paper, Association for Public Policy Analysis and Management.

Hecker, Daniel. 2005. "High-Technology Employment: A NAICS-Based Update." Monthly Labor Review July: 57-72. 
Ho, Andrew Dean, Justin Reich, Sergiy O. Nesterko, Daniel Thomas Seaton, Tommy Mullaney, Jim Waldo, and Isaac Chuang. 2014. "HarvardX and MITx: The First Year of Open Online Courses, Fall 2012-Summer 2013." HarvardX and MITx Working Paper no. 1. http://dspace.mit.edu/bitstream/handle/1721.1/96649/SSRN -id2381263.pdf; sequence $=1$.

Hoxby, Caroline M. 2014. "The Economics of Online Postsecondary Education: MOOCs, Nonselective Education, and Highly Selective Education." NBER Working Paper no. 19816, Cambridge, MA.

2015. "Computing the Value-Added of American Postsecondary Institutions.” SOI working paper, Statistics of Income, US Internal Revenue Service. Accessed Jan. 2017. https://www.irs.gov/pub/irs-soi/15rpcompvalueaddpostsecondary.pdf.

—. 2018. "Online Postsecondary Education and the Higher Education Tax Benefits: An Analysis with Implications for Tax Administration." Tax Policy and the Economy 32 (1): 45-106.

Hoxby, Caroline M., and Christopher Avery. 2013. "The Missing One-Offs: The Hidden Supply of High-Achieving, Low-Income Students." Brooking Papers on Economic Activity (Spring 2013): 1-56.

Long, Bridget Terry, and Angela Boatman. 2013. "The Role of Remediation and Developmental Courses in Access and Persistence." In The State of College Access and Completion: Improving College Success for Students from Underrepresented Groups, edited by Anthony Jones and Laura Perna. New York: Routledge Books.

Looney, Adam, and Constantine Yannelis. 2015. "A Crisis in Student Loans? How Changes in the Characteristics of Borrowers and in the Institutions They Attended Contributed to Rising Loan Defaults." Brookings Papers on Economic Policy, Fall. Accessed Jan. 2017. https://www.brookings.edu/bpea-articles/a-crisis-in-student -loans-how-changes-in-the-characteristics-of-borrowers-and-in-the-institutions -they-attended-contributed-to-rising-loan-defaults/.

McPherson, Michael S., and Lawrence S. Bacow. 2015. "Online Higher Education: Beyond the Hype Cycle.” Journal of Economic Perspectives 29 (4): 135-53.

Miller, Trey. 2009. "On the Validity of Distance to College as an Instrument for Educational Attainment in Models of the Labor Market Return to College." Working paper, RAND, August.

Pew Charitable Trusts. 2016. "Broadband vs. Dial-Up Adoption Over Time." Accessed Jan. 2017. http://www.pewinternet.org/data-trend/internet-use/connection-type/.

Streich, Francie E. 2014. "Online Education in Community Colleges: Access, School Success, and Labor-Market Outcomes." PhD diss., University of Michigan. https://deepblue.lib.umich.edu/handle/2027.42/108944?show=full.

United States Department of Agriculture, Economic Research Services. 2016. Commuting Zones and Labor Market Areas. Online documentation and data. Accessed Jan. 2017. https://www.ers.usda.gov/data-products/commuting-zones-and-labor -market-areas/.

United States General Accountability Office. 2010. For-Profit Colleges: Undercover Testing Finds Colleges Encouraged Fraud and Engaged in Deceptive and Questionable Marketing Practices, GAO-10-948T, Aug. Accessed Jan. 2017. http://www .gao.gov/assets/130/125197.pdf.

2011. For-Profit Schools: Experiences of Undercover Students Enrolled in Online Classes at Selected Colleges, GAO-12-150, Oct. Accessed Jan. 2017. http:// www.gao.gov/assets/590/586456.pdf.

Waldrop, M. Mitchell. 2013. "Massive Open Online Courses, aka MOOCs, Transform Higher Education and Science." Nature magazine, March 13, 1-5.

Wolf, Michael, and Dalton Terrell. 2016. "The High-Tech Industry, What Is It and 
Why It Matters to Our Economic Future." Beyond the Numbers: Employment and Unemployment 5 (8). US Bureau of Labor Statistics, May. Accessed Jan. 2017. https://www.bls.gov/opub/btn/volume-5/the-high-tech-industry-what-is-it-and -why-it-matters-to-our-economic-future.htm.

$\mathrm{Xu}, \mathrm{Di}$, and Shanna Smith Jaggars. 2013. "The Impact of Online Learning on Students' Course Outcomes: Evidence from a Large Community and Technical College System." Economics of Education Review 37:46-57.

\section{Comment Nora Gordon}

Hoxby's research makes an important contribution to our understanding of the role online delivery of higher education plays in the earnings dynamics of the students who use it. This online focus is highly policy relevant: as Hoxby details in the chapter, many have hoped that online education would be a low-cost way to avoid the increasing costs of traditional higher education while effectively - and perhaps even more effectively - providing students with skills needed for current labor market success. The current study provides strong evidence that online education is not going to serve as such a panacea.

Hoxby brings the most comprehensive data to date on earnings dynamics following online enrollment. The present study speaks to a similar set of policy questions as the literature on returns to brick-and-mortar higher education, some of which have been under scrutiny in recent years particularly as they pertain to for-profit colleges. Do students have access to accurate and timely information about how a degree from a particular institution is likely to pay off? Would they make different choices with access to such information? Do institutions of higher education engage in deceitful marketing? Do some institutions devote too many resources to marketing and recruitment, and too few to student supports and instructional quality? Hoxby's analysis suggests online institutions are far from exempt from these familiar problems.

Finally, a critical contribution of this piece is its focus on social returns to online higher education, given the fact that its costs are shared between enrolled students and taxpayers. This is an important point when considering all higher education, including more traditional institutions. While the social costs of student loan default have played prominently in policy discussions, the true full cost to taxpayers includes federal tax expenditures through higher education credits and deductions as well. Hoxby explicitly

Nora Gordon is associate professor at the Georgetown University McCourt School of Public Policy and a research associate of the National Bureau of Economic Research.

For acknowledgments, sources of research support, and disclosure of the author's material financial relationships, if any, please see http://www.nber.org/chapters/c13710.ack. 